\title{
Tau PET imaging in neurodegenerative tauopathies—still a challenge
}

\author{
Antoine Leuzy ${ }^{1} \cdot{\text { Konstantinos Chiotis } \mathbb{D}^{1,2} \cdot \text { Laetitia Lemoine }^{1} \cdot \text { Per-Göran Gillberg }}^{1} \cdot$ Ove Almkvist $^{1,3}$ • \\ Elena Rodriguez-Vieitez ${ }^{1} \cdot$ Agneta Nordberg $^{1,4}$
}

Received: 18 July 2018 / Revised: 19 October 2018 / Accepted: 26 November 2018 / Published online: 11 January 2019

(c) The Author(s) 2019. This article is published with open access

\begin{abstract}
The accumulation of pathological misfolded tau is a feature common to a collective of neurodegenerative disorders known as tauopathies, of which Alzheimer's disease (AD) is the most common. Related tauopathies include progressive supranuclear palsy (PSP), corticobasal syndrome (CBS), Down's syndrome (DS), Parkinson's disease (PD), and dementia with Lewy bodies (DLB). Investigation of the role of tau pathology in the onset and progression of these disorders is now possible due the recent advent of tau-specific ligands for use with positron emission tomography (PET), including first- (e.g., $\left[{ }^{18} \mathrm{~F}\right]$ THK5317, $\left[{ }^{18} \mathrm{~F}\right]$ THK5351, $\left[{ }^{18} \mathrm{~F}\right] \mathrm{AV} 1451$, and $\left.\left[{ }^{11} \mathrm{C}\right] \mathrm{PBB} 3\right)$ and second-generation compounds $\left[\right.$ namely $\left[{ }^{18} \mathrm{~F}\right] \mathrm{MK}-6240,\left[{ }^{18} \mathrm{~F}\right]$ RO-948 (previously referred to as $\left[{ }^{18} \mathrm{~F}\right]$ RO69558948), $\left[{ }^{18} \mathrm{~F}\right] \mathrm{PI}-2620,\left[{ }^{18} \mathrm{~F}\right] \mathrm{GTP} 1,\left[{ }^{18} \mathrm{~F}\right] \mathrm{PM}-\mathrm{PBB} 3$, and $\left[{ }^{18} \mathrm{~F}\right] J \mathrm{NJ} 64349311$ $\left(\left[{ }^{18} \mathrm{~F}\right] \mathrm{JNJ} 311\right)$ and its derivative $\left.\left.\left[{ }^{18} \mathrm{~F}\right] \mathrm{JNJ}-067\right)\right]$. In this review we describe and discuss findings from in vitro and in vivo studies using both initial and new tau ligands, including their relation to biomarkers for amyloid- $\beta$ and neurodegeneration, and cognitive findings. Lastly, methodological considerations for the quantification of in vivo ligand binding are addressed, along with potential future applications of tau PET, including therapeutic trials.
\end{abstract}

\section{Introduction}

The misfolding and accumulation of proteins in the brain is a feature common to a range of neurodegenerative disorders, including a collective characterized by the accumulation of pathological tau. Referred to as tauopathies, the accurate identification of these disorders is a challenge clinically,

These authors contributed equally: Antoine Leuzy, Konstantinos Chiotis

$\triangle$ Agneta Nordberg

agneta.k.nordberg@ki.se

1 Division of Clinical Geriatrics, Center for Alzheimer Research, Department of Neurobiology, Care Sciences and Society, Karolinska Institutet, Stockholm, Sweden

2 Theme Neurology, Karolinska University Hospital, Stockholm, Sweden

3 Department of Psychology, Stockholm University, Stockholm, Sweden

4 Theme Aging, Karolinska University Hospital, Stockholm, Sweden particularly early on in the symptomatic course, because of overlapping clinical phenotypes. The advent of tau-specific ligands for use with positron emission tomography (PET), however, has now made it possible to investigate tau deposition at early stages of several neurodegenerative disorders, including Alzheimer's disease (AD), progressive supranuclear palsy (PSP), corticobasal degeneration (CBD), and related conditions such as Down's syndrome (DS), Parkinson's disease (PD), and dementia with Lewy bodies (DLB). In addition to assisting in the accurate and early differential diagnosis of these disorders, tau imaging may also prove to be of value in the study of tau in the aging brain, in naturalistic studies as a predictor of future cognitive decline, and in therapeutic trials, both for subject selection and as a surrogate outcome measure. In this review, we describe and discuss in vitro and in vivo findings in the brain from investigation of various tau ligands, other biomarkers and cognitive measures, and with respect to methodological considerations tied to the quantification of tau PET.

\section{Tau deposits}

A phosphoprotein involved in the stabilization of microtubules, tau is natively unfolded, with six isoforms divided 
into two functional groups based on the number of repeats [three (3R) or four (4R)] of the microtubule-binding domain [1]. Tau is normally phosphorylated, but hyperphosphorylation weakens its binding to the microtubules and increases its cytosolic levels [2]; following a migration from axonal to somatodendritic compartments, hyperphosphorylated tau assembles into protofibrils [3]. These assemblies are classified as straight, twisted or paired helical filaments (PHFs), based on the absence or periodicity of twists; they are found in neurons, astrocytes, and oligodendroglia [4]. Tau aggregates can assume a range of ultrastructural polymorphisms on the basis of isoform predominance and post-translational modifications [5-9]. Although the mechanisms leading to tau pathology are as yet unclear, experimental evidence implicates abnormalities in kinase and phosphatase activity [10], as well as chronic cerebral hypoperfusion [11], in the hyperphosphorylation of tau; once hyperphosphorylated, decreased microtubule binding results in the increased release of soluble tau species [12]. Transfer of such species between cells has then been shown to occur via synaptic $[13,14]$ and nonsynaptic pathways $[12,15]$, resulting in seeding and the induction of tau aggregation in recipient cells. The accumulation of tau pathology, however, has been postulated to follow stereotypical spatiotemporal patterns. Figure 1 illustrates the tau spreading schemes in AD, PSP, and CBD, as suggested by pathology studies [16-21], although much uncertainty in the exact spreading patterns of tau remains, especially in non-AD tauopathies given the relative paucity of neuropathological data in those diseases in comparison to $\mathrm{AD}$, as well as their neuropathological heterogeneity. According to pathological investigations of tau at autopsy, in vivo tau PET imaging is expected to shed further light on the time course of tau accumulation in relation to other biomarkers and clinical symptomatology.

\section{First- and second-generation tau tracers}

Despite the challenges inherent in imaging tau [22, 23], remarkable progress has been made over the past few years; $\left[{ }^{18} \mathrm{~F}\right]$ FDDNP was the first PET tracer developed to target tau but due to lack of specificity and selectivity in vivo [24], a new set of tau PET tracers was synthetized. The so-called first-generation ligands (e.g., $\left[{ }^{18} \mathrm{~F}\right]$ THK5317, $\quad\left[{ }^{18} \mathrm{~F}\right]$ THK5351, $\left[{ }^{18} \mathrm{~F}\right] \mathrm{AV} 1451$ (also known as $\left[{ }^{18}\right] \mathrm{T}-807,\left[{ }^{18} \mathrm{~F}\right]$ flortaucipir), and $\left.\left[{ }^{11} \mathrm{C}\right] \mathrm{PBB} 3\right)$ have been used extensively in research studies, with second-generation compounds [namely $\left[{ }^{18} \mathrm{~F}\right] \mathrm{MK}-6240,\left[{ }^{18} \mathrm{~F}\right] \mathrm{RO}-948$ (previously referred to as $\left[{ }^{18} \mathrm{~F}\right]$ RO69558948), $\left[{ }^{18} \mathrm{~F}\right] \mathrm{PI}-2620,\left[{ }^{18} \mathrm{~F}\right] \mathrm{GTP} 1,\left[{ }^{18} \mathrm{~F}\right]$ PM-PBB3, and $\left[{ }^{18} \mathrm{~F}\right] J \mathrm{NJ} 64349311\left(\left[{ }^{18} \mathrm{~F}\right] \mathrm{JNJ} 311\right)$, and its derivative $\left.\left[{ }^{18} \mathrm{~F}\right] \mathrm{JNJ}-067\right]$ now entering the field [25-31].

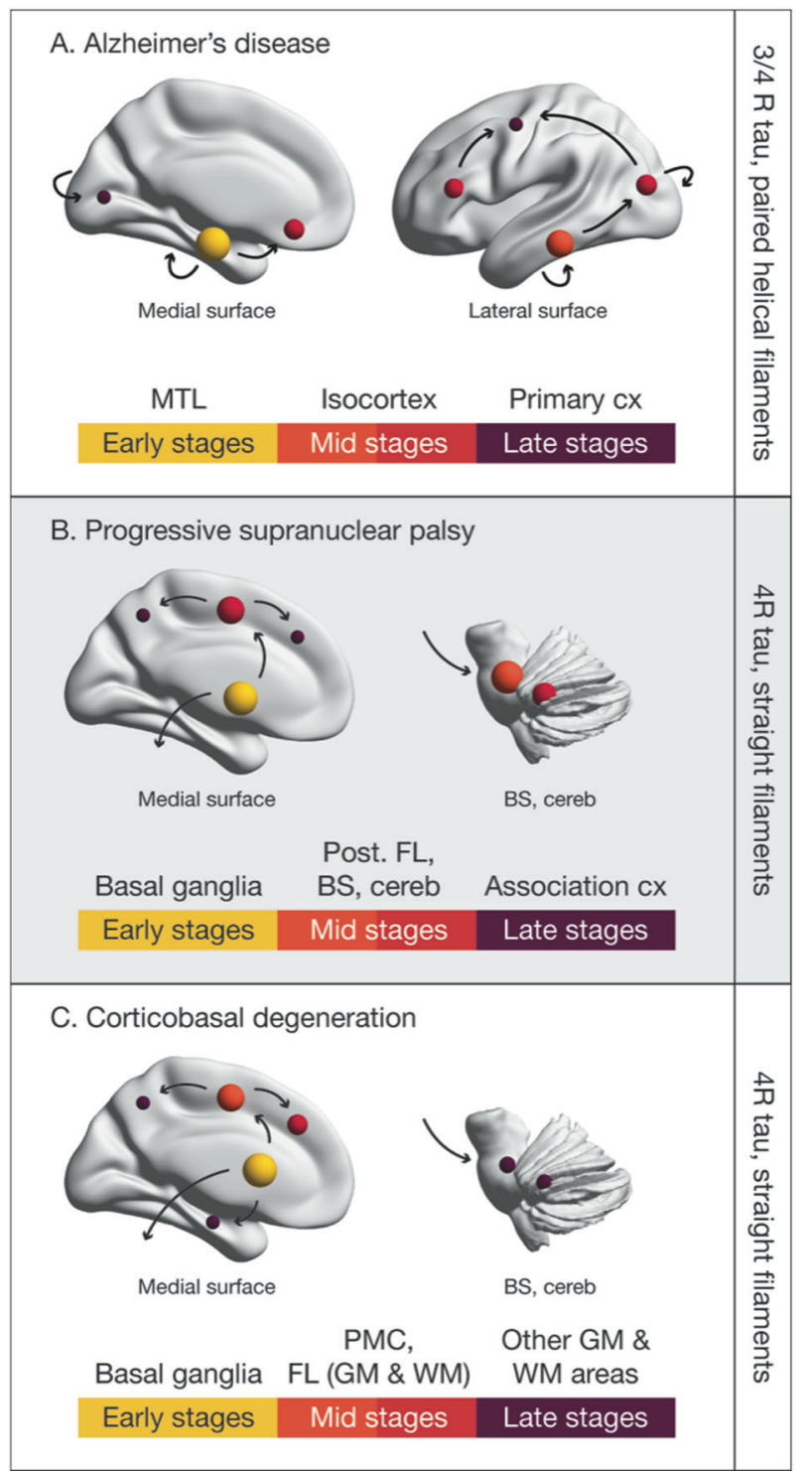

Fig. 1 Spreading schemes for tau pathology in Alzheimer's disease (AD), progressive supranuclear palsy (PSP), and corticobasal degeneration (CBD). The color coding and the size of the spheres distinguishes between brain areas affected at early (yellow; large size), middle (shades of red; mid size) and late (purple; small size) stages of tau propagation. The scheme for AD is adapted from Braak and Braak [60]. The scheme for PSP is adapted from Williams et al. [18]. The scheme for CBD was inspired by the neuropathological studies performed by Forman et al. [19], Kouri et al. [20], and Ling et al. [21]. The label at the right side of each panel indicates the predominant tau isoform affected and the type of tau fibrils formed in AD, PSP, or CBD. For a more detailed description of the neuropathological findings, please refer to Fig. 4. BS brainstem, cereb cerebellum, cx cortex, FL frontal lobe, GM gray matter, MTL medial temporal lobe, PMC primary motor cortex, post. FL posterior frontal lobe, WM white matter

Although the first-generation was promising, some offtarget binding led to the optimization of the binding properties and development of this second-generation of tau tracers followed. Figure 2 shows the chemical structures of 


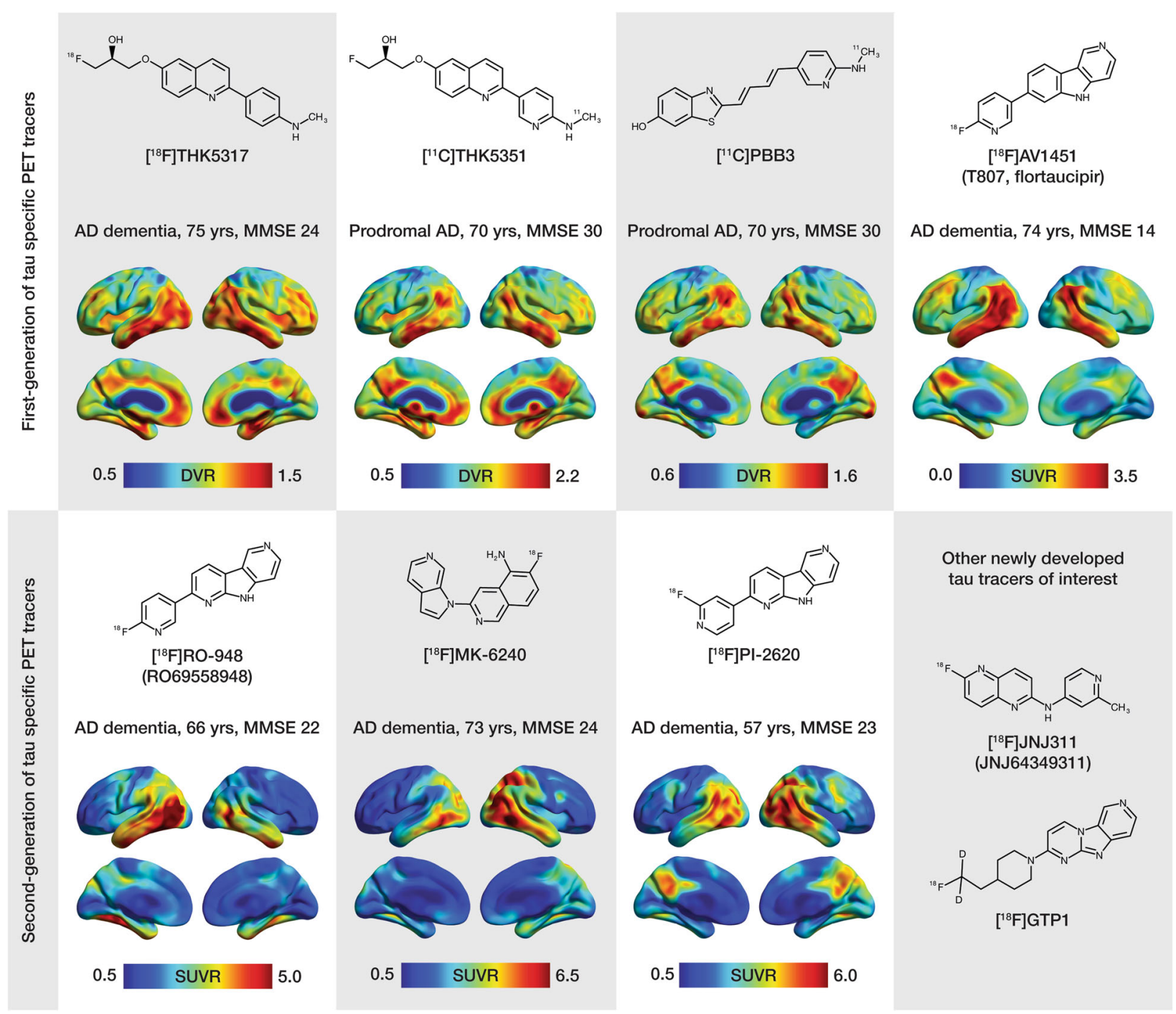

Fig. 2 Chemical structures and representative uptake images in amyloid- $\beta$-positive Alzheimer's disease (AD) patients using selected first- (upper portion of the figure) and second- (lower portion of the figure) generation tau PET tracers. The characteristics in terms of clinical research diagnosis, age and mini mental-state examination (MMSE) scores are presented for each patient above the respective image. For the creation of parametric images for all tracers, areas of the cerebellar cortex were used as reference. The $\left[{ }^{18} \mathrm{~F}\right] \mathrm{THK} 5317,\left[{ }^{11} \mathrm{C}\right]$ THK5351 and $\left[{ }^{11} \mathrm{C}\right]$ PBB3 images derive from studies performed at Karolinska Institutet, Center for Alzheimer Research [35, 153]. The $\left[{ }^{18} \mathrm{~F}\right] \mathrm{AV} 1451$ image is courtesy of the Alzheimer's disease neuroimaging initiative (ADNI). The $\left[{ }^{18} \mathrm{~F}\right] \mathrm{RO}-948$ image is courtesy of Ruben Smith and Oskar Hansson (Lund University, Lund, Sweden). The $\left[{ }^{18} \mathrm{~F}\right]$

the available tau tracers. It is worth noting the differences in the chemical structures of the first-generation tracers. With the aim of developing tracers with better specificity, as discussed below, some of the second-generation tracers were based on the structures of existing tracers (i.e., $\left[{ }^{18} \mathrm{~F}\right]$ RO-948, $\left.\left[{ }^{18} \mathrm{~F}\right] \mathrm{PI}-2620\right)$, but others have relatively different structures (i.e., $\left[{ }^{18} \mathrm{~F}\right] \mathrm{MK}-6240,\left[{ }^{18} \mathrm{~F}\right] \mathrm{JNJ} 311$ ).
MK-6240 and the $\left[{ }^{18} \mathrm{~F}\right] \mathrm{PI}-2620$ images are courtesy of Vincent Doré, Christopher Rowe and Victor Villemagne (University of Melbourne, Victoria, Australia) and Andrew Stephens and Mathias Berndt (Piramal Imaging GmbH, Berlin, Germany), respectively. Different scales were used to better illustrate the regional distribution pattern of binding for each tracer, due to between-patient differences as well as due to the different PET acquisition parameters and quantification methods that were applied for each tracer. Though direct comparison is complicated by these differences, one can observe the preferential binding of the first- and second-generation tracers in AD-relevant areas of the temporal lobes, and the broader dynamic range among secondgeneration tracers. DVR distribution volume ratio, SUVR standardized uptake value ratio

\section{In vitro studies: the what and where of tracer binding}

Extensive in vitro characterization of first-generation tau tracers, using autoradiography on both frozen and paraffin sections of $\mathrm{AD}$ brains in comparison with immunostaining of tau deposits and other hallmarks, was carried out to determine their binding properties. THK5117, THK5351, 
PBB3, and AV1451 (with the lack of labels here, and throughout the text, referring to the molecule itself, whether labeled with carbon-11, fluorine-18, tritium, or unlabeled in competition binding or autoradiography studies) all bind to intracellular and extracellular neurofibrillary tangles (NFTs), as well as to ghost tangles and neuritic plaques [32] (Table 1). Contradictory findings, however, have been reported for binding to pretangles: Ono et al. [33] reported no binding for both PBB3 and AV1451 while, more recently, Wren et al. [34] showed binding of THK5117 and T726, the fluorescent analogue of AV1451. Finally, interas well as intra-case differences were reported in the study of Wren et al. This study emphasized the fact that more detailed and complete investigation of the binding characteristics of the different tau tracers are needed in order to be able to draw conclusions as to their relationship to varied tau characteristics, including the type of tau involved (3R vs. 4R), fibril isoform (paired helical vs. straight vs. twisted), maturity level of the tau deposit (pretangle, mature tangle, and ghost tangle), as well as cell type affected (neurons vs. glia).

\section{In vivo tau PET}

\section{Ageing and $A D$}

First-generation tau tracers Tau imaging in cognitively normal $(\mathrm{CN})$ elderly individuals, using $\left[{ }^{18} \mathrm{~F}\right] \mathrm{THK}$ tracers [35, 36], [ $\left.{ }^{11} \mathrm{C}\right] \mathrm{PBB} 3$ [26], and $\left[{ }^{18} \mathrm{~F}\right] \mathrm{AV} 1451$ [37-48] has consistently shown ligand retention to be largely restricted to the medial temporal lobe (MTL), with cortical findings variable and relatively low [49], or absent altogether [50]. This pattern of MTL binding is consistent with the neuropathological literature [51] and may reflect an age-related process of tau accumulation in this region [52], so-called primary age-related tauopathy [53-56], which has been shown to result in hippocampal atrophy and mild amnestic deficits that are amyloid- $\beta$-independent $[54,57,58]$.

Patients with $\mathrm{AD}$ have significantly higher levels of tau tracer retention than $\mathrm{CN}$ individuals $[25,26,35-37,39,40$, $42,44,59]$ including in the inferior lateral temporal, posterior cingulate, and lateral parietal regions, with binding matching the known regional deposition of tau pathology reported in histopathological studies [51, 60]. Fig. 2 shows sample brain images using different tau tracers for in vivo investigation of patients with $\mathrm{AD}$. Other studies comparing $\mathrm{CN}$ individuals with patients with mild cognitive impairment (MCI) showed differences in binding restricted to MTL regions [39, 40], as well as lateral temporal and parietal areas when examining only amyloid- $\beta$-positive MCI [35]. In a recent large-scale study that examined the discriminative accuracy of $\left[{ }^{18} \mathrm{~F}\right]$ AV1451, for the separation of both MCI due to AD and AD dementia from other neurodegenerative disorders, sensitivity, and specificity estimates were highest using temporal and temporoparietal meta-regions of interest (ROIs) [61]. Group separation was lower in $\mathrm{MCI}$ due to $\mathrm{AD}$, however, owing to less pronounced tracer binding, as compared to AD dementia [61]. In patients with atypical $\mathrm{AD}$ presentations, the spatial pattern of $\left[{ }^{18} \mathrm{~F}\right] \mathrm{AV} 1451$ retention closely matched that in brain regions underlying the different clinical phenotypes [44, 62-67] and had topographical overlap with reduced glucose metabolism patterns [44, 65-67]. In the few studies addressing longitudinal tau PET [68-71], observable increases in tau PET were reported, although significant findings were confined to the subject level in one study [69]. In the largest of these studies [70], tau accumulation rates were found to be rather uniform across brain regions, arguing against the notion that the build-up of tau pathology progresses in a stepwise manner, as suggested by histopathological studies. However, the discrepancy between histopathological and in vivo PET findings could be associated with varied factors relating to the lack of extensive validation of the existing tracers (see section, "Postmortem validation of non-AD tau binding"), or to the fact that this tau staging scheme is based on cross-sectional autopsy data from different brains, thus amounting to an extrapolation only.

Second-generation tau tracers In the studies using secondgeneration tau tracers published to date, which are few [7274], binding of $\left[{ }^{18} \mathrm{~F}\right] \mathrm{RO}-948$ was elevated in medial temporal areas as well as more broadly throughout the cortex, including in the precuneus/posterior cingulate, lateral parietal and occipital lobes, and prefrontal cortex, in four AD patients in comparison to six healthy controls [72]. AD patients showed higher $\left[{ }^{18} \mathrm{~F}\right] \mathrm{RO}-948$ retention in the temporal (hippocampus, entorhinal cortex, parahippocampus, inferior, and middle gyri), medial frontal, and inferior parietal cortices in comparison to older controls. There was increased tracer retention in these regions, in addition to the supramarginal gyrus, precuneus and lateral occipital lobe, in a subset of three $\mathrm{AD}$ patients who underwent follow-up $\left[{ }^{18} \mathrm{~F}\right] \mathrm{RO}-948$ PET $\left(\right.$ median $=21$ months). Using $\left[{ }^{18} \mathrm{~F}\right] \mathrm{MK}$ 6240 , binding patterns consistent with Braak staging of neurofibrillary tau were observed across an amyloid- $\beta$ positive cohort comprising older controls (including those exhibiting cognitive decline), two MCI patients and seven AD patients [73]. Lohith et al. [74] reported similar high $\left[{ }^{18} \mathrm{~F}\right] \mathrm{MK}-6240$ binding in neocortical and medial temporal brain regions in four AD patients, two MCI patients, and four healthy controls. Preliminary in vivo evidence supports binding of $\left[{ }^{18} \mathrm{~F}\right] \mathrm{PI}-2620$ predominantly in the temporal cortex in AD patients (unpublished data). No in vivo human data have been presented for the tracers of the JNJ family yet. Sample images of patients with AD who underwent PET imaging with selected second-generation tau tracers are shown in Fig. 2. 


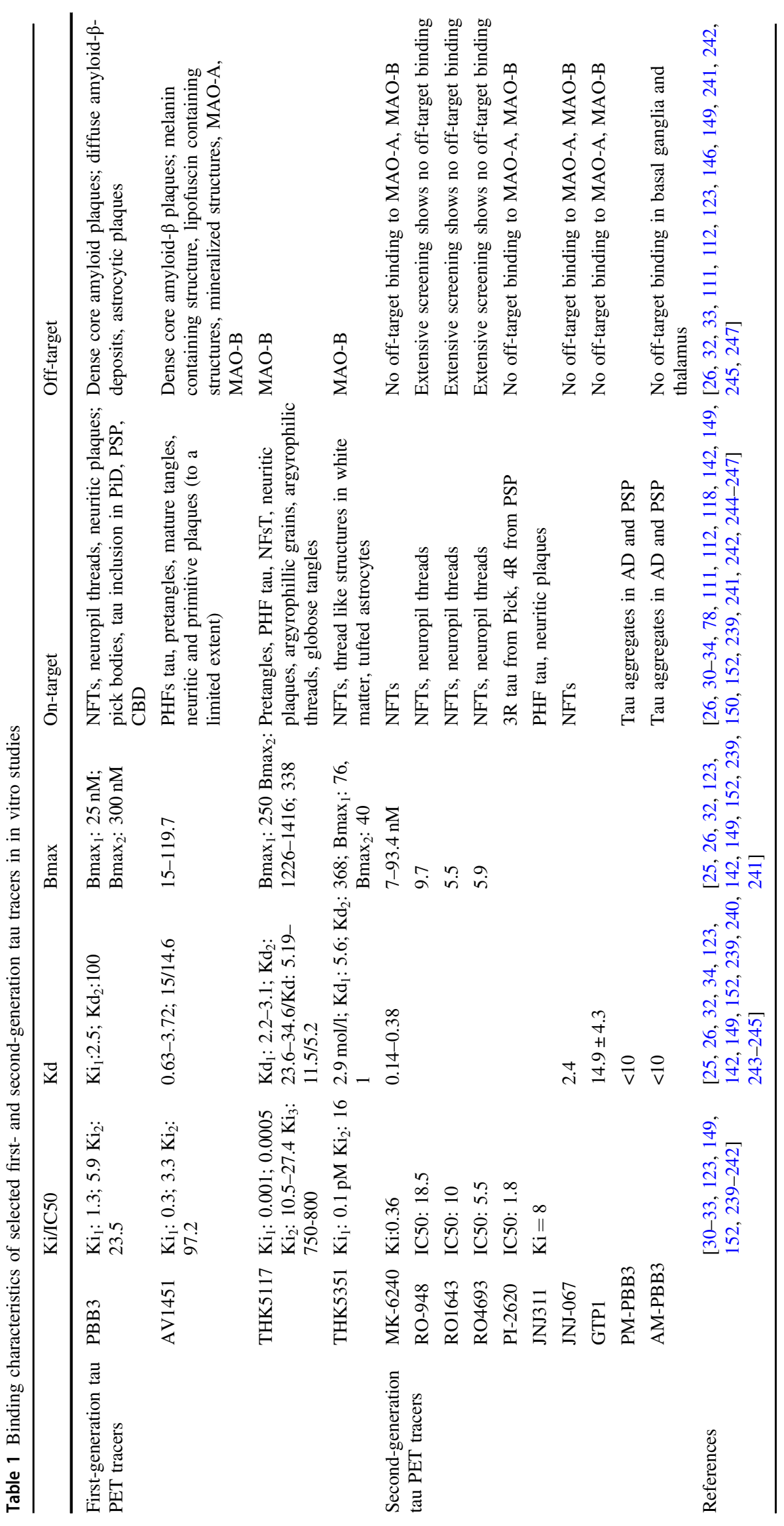




\section{Primary and other tauopathies}

\section{Primary tauopathies}

Although most tau PET studies have been performed in patients with $\mathrm{AD}$, tau imaging should be of clinical value in other more rare neurodegenerative conditions associated with tau pathology such as CBS and PSP [75]. In addition to NFTs composed of PHFs in neurons, as in AD, these neuropathological entities also exhibit tau in glial cells. These deposits consist mainly of $4 \mathrm{R}$ tau, which in turn forms straight tau filaments that are located mainly in subcortical nuclei. As can be observed in Fig. 3, however, there is substantial clinical and neuropathological overlap between these tauopathies, and with other syndromes associated with cognitive impairment, including AD. This renders clinical diagnosis challenging, particularly when combined with the absence of reliable disease-specific biomarkers [76, 77].

So far, PET imaging solely with first-generation tau tracers has been carried out in primary tauopathies. $\left[{ }^{18} \mathrm{~F}\right]$ AV1451, tracers of the $\left[{ }^{18} \mathrm{~F}\right] \mathrm{THK}$ family, and $\left[{ }^{11} \mathrm{C}\right] \mathrm{PBB} 3$ have, in single cases or groups of patients with a clinical diagnosis in the CBS/PSP spectrum, shown the regional pattern of tau pathology expected in these diseases with relatively good discrimination from healthy volunteers $[19$, $26,35,78-88]$. However, given the fact that many of the regions of interest in CBS and PSP largely coincide with areas showing off-target binding [i.e., to monoamine oxidase (MAO)-B in the basal ganglia], there is a wide overlap in the load of tracer binding in those regions across diagnostic groups, especially for $\left[{ }^{18} \mathrm{~F}\right] \mathrm{AV} 1451$, which is the tracer that has been tested in larger patient samples [81, 84, 89]. Longitudinal tau imaging in individual patients with clinical CBS has shown an increase in tracer binding with disease progression [69, 90], while tracer binding in PSP patients correlates well with clinical scores of functional impairment [86, 91], although the latter finding has so far not been replicated in other, larger patient samples with $\left[{ }^{18} \mathrm{~F}\right] \mathrm{AV} 1451[81,83]$.

Chronic traumatic encephalopathy (CTE) is also a neurodegenerative disease associated with the presence of tau pathology (3R and 4R tau) and is secondary to repeated head injuries [92]. Tau PET imaging $\left(\left[{ }^{18} \mathrm{~F}\right] \mathrm{AV} 1451\right)$ has been reported so far only in two cases with clinical diagnosis of CTE, where a somewhat increased tracer binding was found, although with a different regional pattern of binding between patients [93, 94]. The limited evidence available illustrates that extensive work is required for determining the usefulness of tau PET imaging in CTE.

\section{Other tauopathies}

DS, PD, and DLB have been associated with the presence of tau deposits, primarily of the AD type [95-98]. Preliminary evidence in DS with the tracer $\left[{ }^{18} \mathrm{~F}\right] \mathrm{AV} 1451$ indicates that the binding pattern in amyloid- $\beta$-positive patients resembles that observed in $\mathrm{AD}$, increasing with progression of the disease [99]. On the other hand, the $\left[{ }^{18} \mathrm{~F}\right] \mathrm{AV} 1451$ binding in PD and DLB has been largely variable, often producing inconsistencies between studies and overlap with $\mathrm{CN}$ controls [81, 100-105]. These findings are in agreement with the available postmortem data, which indicate a varying degree of tau pathology in these diseases; although the neuropathological presence of tau has been associated with specific clinical phenotypes of DLB/PD in some studies [106, 107], the role of tau in the development of these diseases is not yet clear [108 110]. A note of caution is advised in the interpretation of PD and DLB results, however, given that the affinity of the existing tau tracers for the hallmark pathology observed in these disorders, $\alpha$-synuclein, is not fully understood (for a detailed description, please refer to the section "Tracer specificity for tau").

\section{Postmortem validation of non-AD tau binding}

As described above, in vitro studies performed on AD brain tissue have supported binding to PHF-tau [32]. Most in vitro autoradiography studies in non-AD involved direct comparison with tau immunostaining, and showed that AV1451 was binding with relatively low, if any, affinity to the straight tau filaments of CBS and PSP [111-114]. These findings are in clear contrast to in vivo observations, which raises uncertainty about whether the observed in vivo signal derives from binding to tau or other targets (i.e. nonspecific binding). To add to this uncertainty, there were conflicting results regarding the presence of a correlation between in vivo $\left[{ }^{18} \mathrm{~F}\right] \mathrm{AV} 1451$ binding and postmortem tau load for patients with CBS or PSP who had $\left[{ }^{18} \mathrm{~F}\right] \mathrm{AV} 1451$ imaging and neuropathological assessment of tau burden; $\left[{ }^{18} \mathrm{~F}\right]$ AV1451 PET identified in vivo areas with postmortem high tau in some brain areas and patients but not others, which probably indicates a reduced sensitivity of the tracer to non$\mathrm{AD}$ tau $[81,113,115-117]$. In contrast, in vitro staining and/or autoradiography studies have highlighted the ability of PBB3 and tracers of the THK family to bind to some extent to CBS or PSP tau deposits, in agreement with in vivo findings [26, 33, 78, 118]; this appears to have been confirmed in the first patient with ante-mortem $\left[{ }^{18} \mathrm{~F}\right]$ THK5351 imaging and postmortem assessment of tau pathology [119]. Furthermore, in vitro evidence suggests that PBB3 may have a higher affinity for non-AD tau than AV1451 [33], and preliminary in vivo data suggest that selected THK tracers may be better able to detect non-AD pathology than AV1451 [120]. Overall, in vitro and in vivo evidence (cross-sectional and longitudinal), although somewhat preliminary, suggest that tracers of the THK family, primarily, and, secondarily, $\left[{ }^{11} \mathrm{C}\right] \mathrm{PBB} 3$, may be 


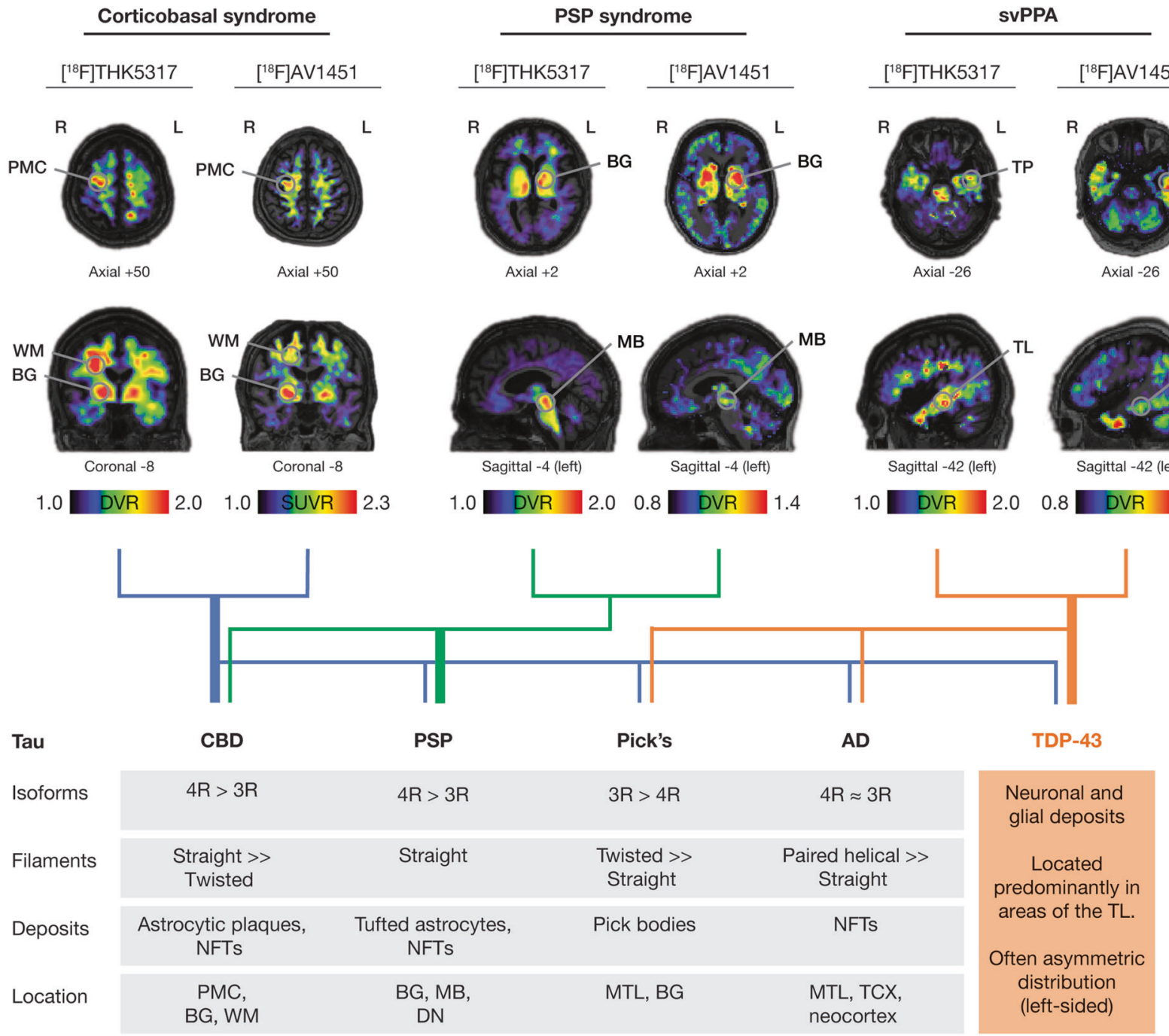

Fig. 3 Representative $\left[{ }^{18} \mathrm{~F}\right]$ THK5317 and $\left[{ }^{18} \mathrm{~F}\right] \mathrm{AV} 1451$ images of amyloid- $\beta$-negative patients with clinical diagnoses of corticobasal syndrome, progressive supranuclear palsy (PSP) syndrome, and a semantic variant of primary progressive aphasia (svPPA) (upper portion of the figure), and a tree diagram (mid portion of the figure) illustrating the poor correlation between the clinical diagnoses of corticobasal syndrome, PSP syndrome, and svPPA with pathological confirmation of the presence of tau [black font; corticobasal degeneration (CBD), PSP, Pick's disease, Alzheimer's disease (AD)], and TDP-43 (orange font) pathologies. The areas with high-tracer uptake are indicated with circles. The thickness of the strings (OR lines) in the diagram illustrates the approximate strength of the clinicopathological correlations [156, 237]. The lower portion of the figure shows the neuropathological and biochemical characteristics of tau pathology seen across a number of tauopathies, as well as some typical neuropathological characteristics of TDP-43 pathology. Of note, different patients were scanned for each tau PET tracer, although one can observe apparent similarities in the regional distribution of tracer uptake for $\left[{ }^{18} \mathrm{~F}\right]$ THK5317 and $\left[{ }^{18} \mathrm{~F}\right] \mathrm{AV} 1451$ in the patients with the same clinical diagnosis. The patients with a clinical diagnosis of corticobasal and PSP syndromes show high binding of both tracers in relevant areas, in agreement with the expected regional distribution

better suited than $\left[{ }^{18} \mathrm{~F}\right] \mathrm{AV} 1451$ for tracking non-AD tau pathology $[26,35,113,118-121]$, although the latter of CBD and PSP pathologies, respectively. Interestingly, high binding with both tracers is observed even in patients with a clinical diagnosis of svPPA, a syndrome which is not primarily associated with the presence of tau, but rather TDP-43 pathology. For the creation of parametric images for all tracers, areas of the cerebellar cortex were used as reference. The $\left[{ }^{18} \mathrm{~F}\right]$ THK5317 images derive from studies performed at Karolinska Institutet, Center for Alzheimer Research [35]. The $\left[{ }^{18} \mathrm{~F}\right] \mathrm{AV} 1451$ images of the patient with corticobasal syndrome is courtesy of Chul Hyoung Lyoo (Yonsei University College of Medicine, Seoul, South Korea) [80], while the $\left[{ }^{18} \mathrm{~F}\right] \mathrm{AV} 1451$ images of the patients with PSP syndrome and svPPA are courtesy of Simon P. Jones and James Rowe (University of Cambridge, Cambridge, UK) $[82,138]$. Different scales were used to better illustrate the regional distribution pattern of binding for each tracer, due to between-patient differences as well as due to the different PET acquisition parameters and quantification that were applied for each tracer or even within the same tracer between different laboratories for $\left[{ }^{18} \mathrm{~F}\right] \mathrm{AV} 1451 . \mathrm{BG}$ basal ganglia, DN dentate nucleus, DVR distribution volume ratio, MB midbrain, PMC primary motor cortex, SUVR standardized uptake value ratio, TL temporal lobe, TP temporal pole, TCX temporal cortex, WM white matter

remains to be confirmed by ante-/post-mortem findings in CBS and PSP. 
A direct comparison of in vivo and in vitro results, however, is not straightforward due the different methodological parameters of these techniques. In vitro binding studies performed with homogenates and autoradiography, for instance, can give different results caused by the washing away of extracellular proteins in homogenatebased analyses, but not in autoradiography tissue sections. In addition, results can be widely influenced by the concentration of ethanol in the incubation buffer, the purity of tritiated compounds (which can decrease over time in contrast to carbon-11 and fluorine-18 labeled PET compounds, which are custom synthesized on the day of the experiment), and choice of paraffin (including pretreatment, heat and fixation of the tissue) vs. frozen sections [122]. Indeed, a recent study highlighted the importance of experimental design for in vitro studies, showing that the concentration of ethanol used determined concordance with in vivo findings [122]. As a further example, when Harada et al. performed their initial evaluation of the THK tracers on paraffin sections, evidence of potential off-target binding of the tracer to MAO-B was not detected (personal communication, Ryuichi Harada). Conversely, when the same evaluation was performed on frozen tissue, a competition of the tracer with a MAO-B inhibitor was apparent, as discussed below, in agreement with in vivo studies $[35,123$, 124].

As recently pointed out in a commentary by Klunk [125], there is still a lack of extensive experimental and clinical validation of different tau PET tracers. Some of the differences might be due to tracer metabolism and lipophilicity, a case in point being $\left[{ }^{11} \mathrm{C}\right] \mathrm{PBB} 3$, where the estimation of brain retention is complicated by the presence of a brain penetrant radioactive metabolite $[26,126,127]$. There is also assumptions pertaining to the relationship between semi-quantitative estimates and findings from arterial input modeling that likely do not always hold (e.g., the commonly used late frame quantification of tracers and the actual measures of tracer binding, show only moderate correlation for tracers of the THK family [128] and a nonlinear relationship for $\left[{ }^{18} \mathrm{~F}\right]$ AV1451) [129, 130]. Together, these elements limit, to some extent, the interpretation of existing cross-sectional and longitudinal data. Finally, in addition to the fact that in vivo and in vitro studies, such as autoradiography and immunostaining, are likely capturing different stages of pathology - with postmortem studies limited to a single time point, most often at the end stage of the diseasethey cannot be directly compared as antibodies are targeting specific epitope and phosphorylation sites, whereas PET tracers bind to varied molecular sites. We do believe that in vitro studies are necessary, however, and that experimental efforts need to be devoted to better understanding which aspects may contribute to discrepancies between in vivo and in vitro evidence for current tau tracers.

\section{Tracer specificity for tau}

Off-target binding to non-tau protein deposits The existing tau tracers are small molecules and although we think of them as specific to tau itself, their specificity is actually based on the structure of the tau $\beta$-sheet that is adopted when tau forms the different kinds of fibrils in $\mathrm{AD}$ or other tauopathies. However, this structure is not unique to tau but is also present in the fibrils formed by amyloid- $\beta$, TDP-43, $\alpha$-synuclein, etc [131]. As an example, $\left[{ }^{18} \mathrm{~F}\right] \mathrm{FDDNP}$, which was the first tracer injected in vivo with affinity for tau pathology [132-134], and was developed several years before the reviewed first and second-generation tau tracers, showed a lack of specificity for tau over other $\beta$-sheet structures $[135,136]$, which limited the interest in its further development. Such specificity issues should serve as a didactic example, indicating that the need for extensive validation of the binding characteristics of the tau tracers currently under development. Interestingly, the first in vitro studies of the first-generation tau tracers highlighted a selective binding to tau rather than to other fibrils [111, 112, 118], but increasing evidence now indicates that these tracers can potentially bind to other protein deposits. For instance, both $\left[{ }^{18} \mathrm{~F}\right] \mathrm{AV} 1451$ and fluorine-18 THK ligands have demonstrated a similar characteristic regional binding pattern in vivo in PET studies of a series of patients with a semantic variant of primary progressive aphasia (svPPA), a clinical syndrome associated predominantly with TDP-43 pathology rather than tau pathology (Fig. 3) [86, 137-139]. Furthermore, $\left[{ }^{18} \mathrm{~F}\right] \mathrm{AV} 1451$ and $\left[{ }^{11} \mathrm{C}\right] \mathrm{PBB} 3$ have shown in vivo binding in patients expected to have $\alpha$-synuclein deposits [140, 141], which is in agreement with some more recent in vitro studies, at least for $\left[{ }^{11} \mathrm{C}\right] \mathrm{PBB} 3$ - so far, however, autoradiography results do not confirm a similar in vitro binding of THK5351 and AV1451 to $\alpha$-synuclein deposits [33, 111, 142, 143].

While observations with $\left[{ }^{18} \mathrm{~F}\right] \mathrm{AV} 1451$ and $\left[{ }^{11} \mathrm{C}\right] \mathrm{PBB} 3$ remain to be validated in ante-/post-mortem studies, they raise concerns that the different tau tracers might bind in vivo to multiple $\beta$-sheet structures, a finding that would limit their clinical utility in discriminating between both different protein deposits - which regularly coexist in different proportions in the neurodegenerating brain irrespective of the driving pathology [144] —and different proteinopathies. Furthermore, binding of the tracers to multiple $\beta$-sheet structures could limit the interpretation of studies investigating the association between those different co-existent pathologies (i.e., amyloid$\beta$, tau, $\alpha$-synuclein, and TDP-43) in patients with cognitive complaints, and especially those looking into the association between tau and amyloid- $\beta$ in $\mathrm{AD}$ (studies discussed below), where both pathologies are involved and are often colocalized. 
Off-target binding to other molecular structures Offtarget binding to molecular structures other than tau protein deposits discussed above have been reported for firstgeneration tracers, in particular to MAO-B enzyme in the basal ganglia (Fig. 4), a finding that has been validated in vitro, at least for the THK tracers and $\left[{ }^{18} \mathrm{~F}\right] \mathrm{AV} 1451[124$,
145]. This could limit the clinical validity of these PET tracers, at least in diseases where tau deposition is expected in areas with a high load of MAO-B (e.g., CBS and PSP); the potential implications of this with respect to the interpretation of isocortical signal, however, remains unclear [146]. Although off-target binding of second-generation

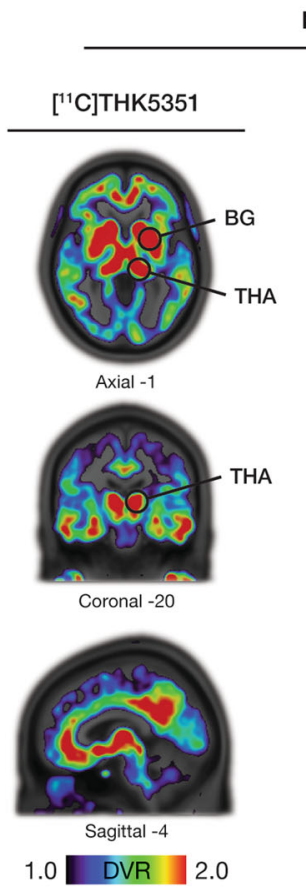

First-generation of tau PET tracers

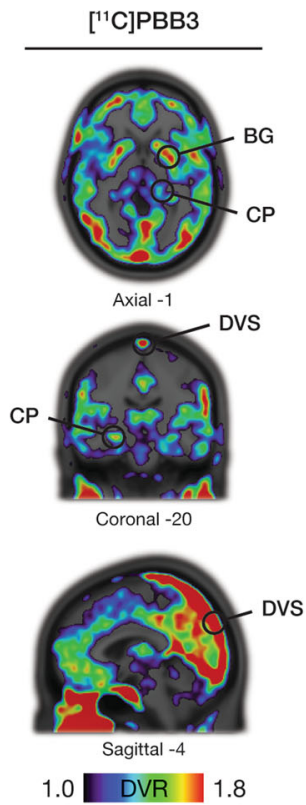

Off-target areas
BG / THA
(MAO-B)
Choroid plexus
(biondi ring tangles)
Dural venus
sinuses
SN
(Neuromelanin)

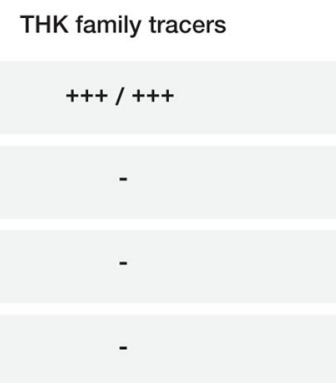

$\left[{ }^{11} \mathrm{C}\right] \mathrm{PBB} 3$

Fig. 4 Off-target binding of selected first- (left portion of the figure) and second (right portion of the figure) -generation tau PET ligands. Images are taken from amyloid- $\beta$-positive Alzheimer's disease (AD) patients; research clinical diagnosis, age, and mini-mental state examination results are as follows: $\left[{ }^{18} \mathrm{~F}\right] \mathrm{THK} 5351$, prodromal AD, 70, 30; (Karolinska Institutet, Center for Alzheimer Research); [35] [ $\left.{ }^{11} \mathrm{C}\right]$ PBB3 prodromal AD, 53, 27 (Karolinska Institutet, Center for Alzheimer Research); [153] $\left[{ }^{18} \mathrm{~F}\right] \mathrm{AV} 1451, \mathrm{AD}$ dementia, 79, 22 (image courtesy of ADNI); [ $\left.{ }^{18} \mathrm{~F}\right] \mathrm{RO}-948$, AD dementia, 66, 22 (image courtesy of Oskar Hansson and the Swedish BioFINDER study); $\left[{ }^{18} \mathrm{~F}\right] \mathrm{MK}-$ 6240, AD dementia, 73, 24 and $\left[{ }^{18} \mathrm{~F}\right] \mathrm{PI}-2620, \mathrm{AD}$ dementia, 57, 23 (images courtesy of Christopher Rowe and Victor Villemagne). The main areas of known off-target binding for the second-generation tau tracers are marked with circles. The load of this off-target binding across the different tracers is graded in a semiquantitative manner in a table in the lower portion of the figure. Specific non-tau targets for this binding have been reported as briefly named in parentheses and

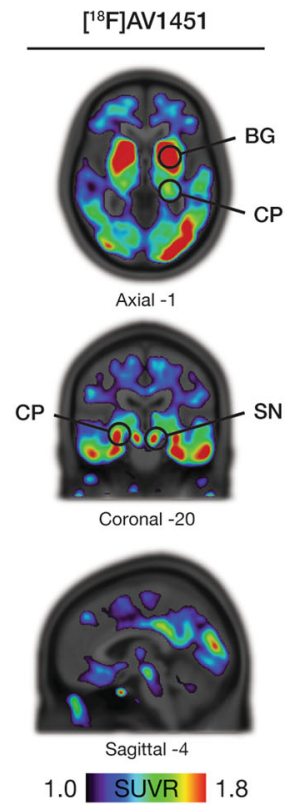

Second-generation of tau PET tracers
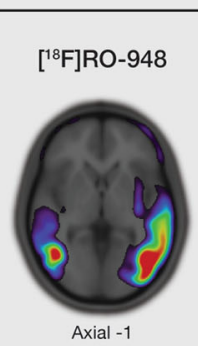

$2.0 \lcm{\text { SUVR }} 5.0$

$\left[{ }^{18} \mathrm{~F}\right] \mathrm{MK}-6240$

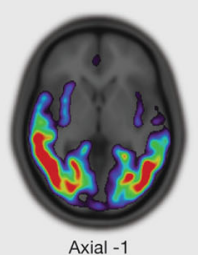

2.0 SUVR 6.0

$\left[{ }^{18} \mathrm{~F}\right] \mathrm{PI}-2620$

$\left[{ }^{18} \mathrm{~F}\right] \mathrm{AV} 1451$

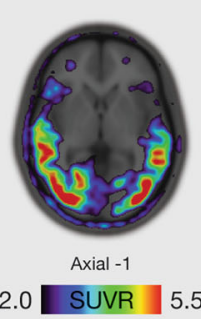

illustrated in detail in Table 1. The wider dynamic range of the secondgeneration tau tracers can be seen as well as the lower binding in the MAO-B rich basal ganglia (BG) and thalamus (THA). Different scales were used to better illustrate the regional distribution pattern of binding for each tracer, due to between-patient differences as well as due to the different PET acquisition parameters and quantification that were applied for each tracer. Other reported off-target binding areas for the second-generation tau tracers are not presented in this figure [27, 29]. Areas of the cerebellar cortex were used as reference for creating parametric images for all the tracers. CP choroid plexus, DVS dural venous sinuses, SN substantia nigra, BG basal ganglia, DN dentate nucleus, DVR distribution volume ratio, MB midbrain, NFTs neurofibrillary tangles, PMC primary motor cortex, R repeats of the microtubule-binding domain, SUVR standardized uptake value ratio, TL temporal lobe, TP temporal pole, TCX temporal cortex, WM white matter 
tracers has yet to be described in detail, they are thought to be associated with a lower, or no, signal in MAO-B-rich areas (Fig. 4).

An off-target signal has been reported for first-generation tau tracers in vascular structures (choroid plexus for $\left[{ }^{11} \mathrm{C}\right]$ PBB3 and $\left[{ }^{18} \mathrm{~F}\right] \mathrm{AV} 1451$, and the dural venous sinuses for $\left[{ }^{11} \mathrm{C}\right] \mathrm{PBB} 3$, attributable to biondi ring tangles, hemosiderin, melanocytes, etc. [32, 147]), with this potentially affecting accurate quantification of tracer binding in the relevant areas (e.g., MTL and isocortex) [72, 73]. $\left[{ }^{18} \mathrm{~F}\right] \mathrm{AV} 1451$ and its derivatives from the second-generation (e.g., $\left[{ }^{18} \mathrm{~F}\right] \mathrm{RO}$ 948) have been associated with binding to neuromelanin, however, which could indicate that these tracers would be useful in PD because of the characteristic loss of neuromelanin-rich neurons of the substantia nigra [72, 104, 105, 147].

Comparison of tau tracer binding in silico, in vitro, and in vivo The recent publication of the cryo-electron microscopy structure of tau filaments derived from $\mathrm{AD}$ patients [148] has opened a new path for designing tau PET tracers and investigating the different binding sites. Predicted binding affinities are in the nanomolar range, which is in agreement with certain experimental inhibition constant data reported for these tracers [26, 27, 142, 149, 150]. Further, using in silico modeling, Murugan et al. [151] have shown four different high-affinity binding sites on the tau protofibril (Fig. 5). AV1451 and MK-6240 appear to bind to site 1 with higher binding affinity, results that are in line with those of Hostetler et al. [149], who suggested that they could bind to a similar binding site. The THK5351 tracer binds strongly to sites 1 and 3 , with site 3 being the preferred site. Results from Murugan et al. [151] suggest that PBB3 binds to the 4 sites with similar affinity, while the other tracers appear to have one or two main binding sites. Further studies are needed to compare binding data from in silico modeling of tau fibrils with data from in vitro and in vivo binding studies in the human brain. In silico computer modeling may provide new tau tracers with favorable properties for PET.

In vitro binding assays using tau fibrils or human brain homogenate and human brain sections have demonstrated that the tau tracers have good binding properties in the nanomolar range (Table 1) and suggested several binding sites for first-generation PET tau tracers. There were at least three binding sites for THK5117 [152], and at least two for PBB3 [33]. A head-to-head comparison of THK (5117, the racemic form of THK5317, and 5351) compounds, PBB3 and AV1451 in postmortem AD brain tissue showed an interaction between AV1451 and THK5351, while PBB3 showed distinct binding properties [123]. A study by Ono et al. suggested that PBB3 can bind 4R tau (CBD/ PSP), while AV1451 cannot, despite both showing similar

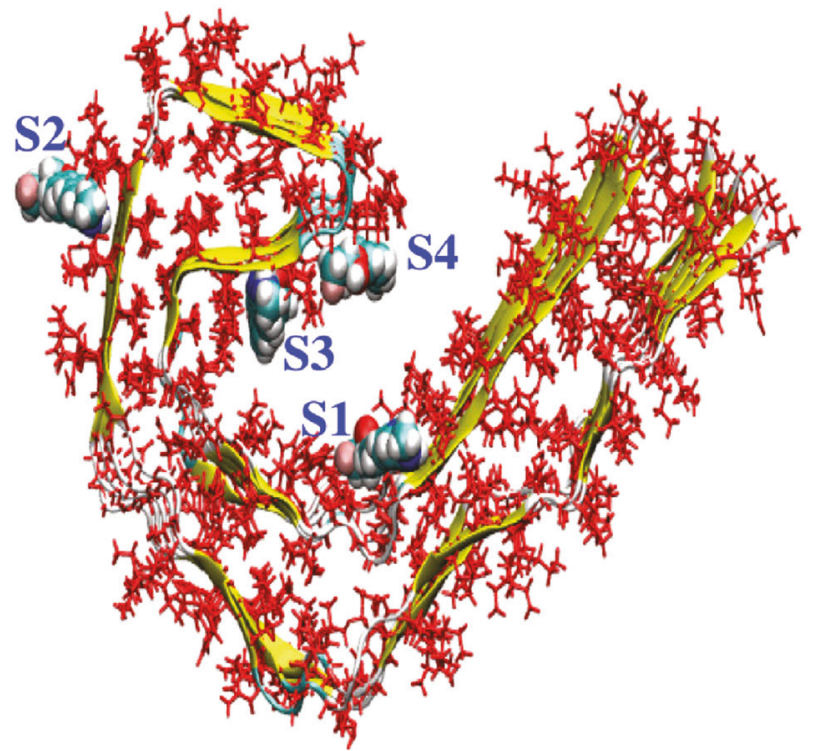

Fig. 5 Representation of a tau protofibril, showing four high-affinity binding sites (core sites: 1, 3, and 4; surface site, 2) for tau PET ligands, as determined via in silico modeling. With the exception of $\left[{ }^{18} \mathrm{~F}\right] \mathrm{T} 808$, all the studied tracers $\left(\left[{ }^{18} \mathrm{~F}\right] \mathrm{AV} 1451,\left[{ }^{18} \mathrm{~F}\right] \mathrm{FDDNP},\left[{ }^{11} \mathrm{C}\right]\right.$ PBB3, $\left[{ }^{18} \mathrm{~F}\right]$ THK5105, $\left[{ }^{18} \mathrm{~F}\right]$ THK523, $\left[{ }^{18} \mathrm{~F}\right]$ THK5351, $\left[{ }^{18} \mathrm{~F}\right]$ THK5117, $\left[{ }^{18} \mathrm{~F}\right] \mathrm{MK}-6240,\left[{ }^{18} \mathrm{~F}\right] \mathrm{RO}-948$, and $\left.\left[{ }^{18} \mathrm{~F}\right] \mathrm{JNJ} 311\right)$ have shown significant binding to these four sites. On the basis of molecular docking scores, however, tracers such as $\left[{ }^{18} \mathrm{~F}\right] \mathrm{FDDNP},\left[{ }^{18} \mathrm{~F}\right] \mathrm{THK} 5351,\left[{ }^{18} \mathrm{~F}\right] \mathrm{RO6955}$, and $\left[{ }^{18} \mathrm{~F}\right] \mathrm{MK}-6240$ bind preferentially to the core sites, while $\left[{ }^{11} \mathrm{C}\right]$ $\mathrm{PBB} 3$ and $\left[{ }^{18} \mathrm{~F}\right] \mathrm{THK} 523$ bind preferentially to site 2 . Certain ligands, moreover, such as $\left[{ }^{18} \mathrm{~F}\right]$ THK5317 and $\left[{ }^{18} \mathrm{~F}\right] J N J 311$, show similar binding affinities to several sites. Adapted with permission from American Chemical Society Publications, Murugan et al. [151]. (ACS Chem Neurosci. 2018. Copyright 2018)

binding in AD [33]. A direct comparison of MK-6240 and AV1451 showed that they most probably bind to the same site [149]. The tau tracers showed several binding sites, one with very high affinity $(\mathrm{pM})$, another with intermediate $\mathrm{Kd}$ values between 5 and $20 \mathrm{nM}$ (probably the one that is observed in PET studies), and one with low affinity ( $\mathrm{Kd}>$ $100 \mathrm{nM})$. More in vitro characterization is needed to better understand these different binding sites, as well as their relationship to binding patterns seen with different tau tracers in vivo.

In vivo, the tau tracers of the first generation are distributed similarly when injected into patients with $A D$, as discussed above (Fig. 2). However, when tracers from the THK family, $\left[{ }^{18} \mathrm{~F}\right] \mathrm{AV} 1451$ and $\left[{ }^{11} \mathrm{C}\right] \mathrm{PBB} 3$ where injected into the same individuals in head-to-head designs, a number of substantial differences in their tracer characteristics, as well as in their relationships with other markers of the disease, were noted $[120,153]$. While the binding distribution patterns for tracers of the THK family and $\left[{ }^{18} \mathrm{~F}\right] \mathrm{AV} 1451$ appeared to be similar and highly correlated in terms of binding load, the regional distribution pattern for 
$\left[{ }^{11} \mathrm{C}\right] \mathrm{PBB} 3$ was different, and there was no correlation with THK tracers for the binding load, which indicates the potentially different molecular targets for $\left[{ }^{11} \mathrm{C}\right] \mathrm{PBB} 3$ relative to the targets for tracers of the THK family and $\left[{ }^{18} \mathrm{~F}\right] \mathrm{AV} 1451$, in agreement with in vitro and in silico simulation studies. Comparison of the binding characteristics of second-generation tracers in vivo remains to be carried out.

\section{Tau PET in relation to other biomarkers}

$A / T / N$ : a staging scheme for AD biomarkers In the light of recent scientific advances, a biomarker-driven research framework has been proposed [154] to update and unify the diagnostic criteria for AD recommended in 2011 by the National Institute on Aging and Alzheimer's Association (NIA-AA) [115, 155-158]. According to the new so-called A/T/N (i.e., amyloid- $\beta /$ Tau/Neurodegeneration) classification scheme, biomarkers can be grouped into those for amyloid- $\beta$ [A; elevated amyloid- $\beta$ levels, as measured by PET or low cerebrospinal fluid (CSF) amyloid- $\beta_{1-42}$ or amyloid- $\beta_{1-42} /$ amyloid- $\beta_{1-40}$ levels], abnormal tau [T; elevated tau PET or CSF phosphorylated tau (p-tau) levels], and neurodegeneration [N; hypometabolism on $\left[{ }^{18} \mathrm{~F}\right] \mathrm{FDG}$ PET, atrophy on magnetic resonance imaging (MRI), or elevated CSF total tau (t-tau) levels]. The A/T/N criteria thus allow staging of $\mathrm{AD}$ based solely on biomarkers.

Though the $\mathrm{A} / \mathrm{T} / \mathrm{N}$ framework assumes biomarker interchangeability, it recognizes a temporal delay between CSF and PET measures, with increases in soluble levels of amyloid- $\beta$ and tau pathology preceding changes in PET based markers [159-167]. While this framework acknowledges the conviction shared by many in the field that amyloid- $\beta$ drives the pathogenesis of $\mathrm{AD}$, with pathological tau occurring as a secondary event, proximate to neurodegeneration and cognitive decline (Fig. 6), it also states that the other pathological sequences may be possible. Indeed, within the histopathological literature, both amyloid- $\beta$ [168] and tau-centric [169] outlooks have been articulated. In a third perspective, multiple, as opposed singe pathological mechanisms, (i.e., amyloid- $\beta$ or tau) have been proposed to underlie the majority of dementia cases [170]. Related findings have also been described whereby tau in fact precedes amyloid- $\beta$ in the brainstem and MTL [171]. Though the predominant biomarker based model of AD postulates that markers of amyloid- $\beta$ are abnormal first, followed by tau and neurodegeneration [154, 172], its most recent iteration recognizes that tau may well precede amyloid- $\beta$, with these detected by immunohistology, but not current biomarkers, due its greater sensitivity [172]. As such, the partly differing time-dependent trajectories for amyloid- $\beta$ and tau-tangle pathology suggested by biomarker

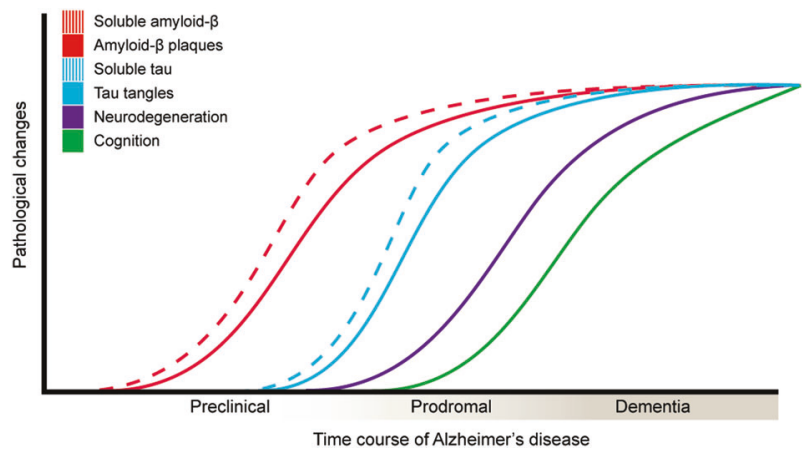

Fig. 6 Hypothetical time course of pathological changes in Alzheimer's disease (AD), in which biomarkers for amyloid- $\beta$ become abnormal [cerebrospinal fluid (CSF) amyloid- $\beta_{1-42}$ preceding PET], followed by abnormal tau (CSF p-tau preceding PET), neurodegeneration, and cognitive decline. Adapted with permission from Jack et al. [182] and 2013 [172], Nordberg [238], and McDade and Bateman [235]

and histopathological data may relate as much to personal viewpoints as to detection thresholds $[173,174]$.

Amyloid- $\beta$ There is now increasing evidence supporting the hypothesis that amyloid- $\beta$ instigates the spread of tau beyond the MTL [37, 70, 175-177], and many in vivo imaging studies are aiming to investigate the effects of the interactive and possibly synergistic relationship between amyloid- $\beta$ and tau on disease severity and progression. However, neocortical tau has been observed in a proportion of amyloid- $\beta$-negative $\mathrm{CN}$ individuals [177], contrary to the expected neuropathological Braak staging scheme, indicating greater heterogeneity in patterns of tau deposition than previously thought. In terms of their comparative regional distributions, though both amyloid- $\beta$ and tau are elevated in neocortical regions, amyloid- $\beta$ is spread diffusely throughout the neocortex, with tau pathology more selective for clinically affected brain regions $[35,38,42,44,65,67$, 178-180]. When graph theory was used to investigate local and distributed network connections, PET-based measures of amyloid- $\beta$ and tau were strongly correlated in the inferior-lateral temporal and entorhinal cortices, with tau accumulation in those regions being associated with widespread cortical amyloid- $\beta$ [46]. Further, both showed hierarchical organization, overlapping in heteromodal association regions [181]. Indeed, while high tau has been shown within temporal regions in the absence of elevated amyloid- $\beta$ levels, high-neocortical tau is associated with elevated amyloid- $\beta$ levels, indicating that the deposition of amyloid- $\beta$ precedes that of tau within cortical areas [178]. Studies have shown high inter-subject variability in amyloid- $\beta$ and tau patterns, however, and while most AD patients present high amyloid- $\beta$ and high tau $[37,42]$, about $15-20 \%$ of amyloid- $\beta$-positive probable AD subjects have low tau levels [178]; this may relate to low binding site 
concentrations or the ability of tau tracers bind varied tau conformations [178].

Overall, the accumulation of in vivo data on regional tau distribution is substantially contributing to the shedding of light onto differential biological mechanisms behind cerebral tau accumulation and spreading, in both the absence and presence of amyloid- $\beta$. The new in vivo PET data are allowing the testing of pathological spreading models that were built based only on postmortem neuropathological data [60], and are thus providing a new experimental paradigm for understanding the progression of the disease. Progress in understanding the regional and temporal relationships between amyloid- $\beta$ and tau will be facilitated by further research incorporating more longitudinal data, and applying more detailed statistical approaches to interpret the complex dynamics of these proteinopathies. In particular, promising approaches may include data-driven methods, and mixed-effects model analysis that would allow for non-linear modeling of the temporal evolution of tau pathology as well as its relationship with other markers of the disease, as previously done with amyloid- $\beta$ PET [172, 182]. Graph theory analysis especially in longitudinal data could shed new light on the in vivo local and distant associations between amyloid- $\beta$ and tau, as well as on the temporal propagation of tau pathology especially when applied to inter-individual longitudinal data [181]. Finally, despite their more theoretical nature, mediation analyses could be used to examine potential causal relationships between pathological processes, as indexed by biomarkers [183, 184].

Tau (CSF P-tau) The A/T/N classification scheme suggests that CSF p-tau and tau pathology follow in the time course of disease development after amyloid- $\beta$ pathology. Several studies have now addressed the relationship between tau imaging ( $\left[{ }^{11} \mathrm{C}\right]$ THK5351 and $\left[{ }^{18} \mathrm{~F}\right] \mathrm{AV} 1451$ binding) and CSF p-tau levels [41, 153, 166, 185-187]; there is a moderate to strong positive correlation between these biomarkers across $\mathrm{CN}$ subjects and varied patient groups $\mathrm{AD}$ (prodromal and dementia), amyloid- $\beta$-negative MCI, dementia of unclear aetiology, and several non-AD disorders (PSP, CBS, and frontotemporal dementia). When only $\mathrm{CN}$ individuals are examined, however, only Chhatwal et al. have shown significant associations [41, 166, 187]. Similarly, when Braak staging was used for AD patients, significant correlations were found only in those at the dementia stage (Braak III, V, and I-V combined) [166]. This may reflect greater variability in CSF p-tau levels among patients with $\mathrm{AD}$ dementia; indeed, many in this group showed p-tau values that, while elevated, were below the cut-off. Furthermore, although overall concordance between $\left[{ }^{18} \mathrm{~F}\right] \mathrm{AV} 1451$ binding and $\mathrm{p}$-tau measurement was greater in $\mathrm{AD}$ dementia patients compared to those with prodromal
$\mathrm{AD}$, a higher proportion showed isolated $\left[{ }^{18} \mathrm{~F}\right] \mathrm{AV} 1451$ positivity [166]. This was in contrast to prodromal AD, where the opposite pattern of discordance was predominant. This finding fits with recent data showing that the symptomatic phase of $\mathrm{AD}$ is characterized by a decrease in CSF tau levels [188]; this may relate to a slowing in neuronal loss and/or the sequestration of p-tau in tangles [186]. In a study similar to that by Mattsson et al. [166], increased $\left[{ }^{18} \mathrm{~F}\right]$ AV1451 binding, but not increased CSF p-tau levels, was associated with lower MMSE scores in AD patients [186], lending support to this idea. At this stage, it is unclear how discordance between tau biomarkers will be treated in the application of the $\mathrm{A} / \mathrm{T} / \mathrm{N}$ scheme. Although it has been suggested that, given the chronicity of $\mathrm{AD}$, concordance will occur over time [154], longitudinal studies using serial CSF sampling are required to address this.

In the studies that addressed the diagnostic accuracy of $\left[{ }^{18} \mathrm{~F}\right] \mathrm{AV} 1451$ binding and CSF p-tau [185, 186], although both biomarkers performed equally well in separating prodromal $\mathrm{AD}$ from control subjects, $\left[{ }^{18} \mathrm{~F}\right] \mathrm{AV} 1451$ was superior for diagnosing $\mathrm{AD}$ dementia [185], suggesting that the diagnostic value of these biomarkers may vary with the disease stage. The fact that CSF p-tau did not differentiate between prodromal $\mathrm{AD}$ and $\mathrm{AD}$ dementia, while the $\left[{ }^{18} \mathrm{~F}\right]$ AV1451 signal was higher for AD dementia, suggests that p-tau could prove to be a suitable state marker (reflecting disease intensity), while $\left[{ }^{18} \mathrm{~F}\right] \mathrm{AV} 1451$ could be useful as a stage marker (reflecting disease progression) [189], given that its binding is elevated at the prodromal stage with further increases through mild-to-moderate dementia [166]. In the only study to include non-AD subjects, high agreement was found between the $\left[{ }^{18} \mathrm{~F}\right]$ AV1451 standardized uptake value ratio and CSF p-tau measurements in differentiating the non-AD subjects from amyloid- $\beta$-positive $\mathrm{AD}$ patients, suggesting that these measures are largely reflective of $\mathrm{AD}$-specific PHF tau pathology [186]. Given the recognition of a range of different tau fragments in the CSF characterized by differing kinetic profiles [188, 190], however, it may be that novel measures are required to ensure adequate concordance with tau imaging.

Neurodegeneration In a study in $\mathrm{CN}$ subjects, tau and amyloid- $\beta$ were found to interact; when both were increased, metabolism in the posterior cingulate cortex was decreased, which predicted AD-like memory decline [191], consistent with findings in AD [192]. In contrast, frontal hypometabolism was associated with the common agerelated entorhinal tauopathy, independent of amyloid- $\beta$ and without memory decline. In $\mathrm{AD}$ patients, studies have shown a close correspondence between $\left[{ }^{18} \mathrm{~F}\right] \mathrm{AV} 1451$ binding and hypometabolism across most neocortical regions $[44,65,67,192]$ and between $\left[{ }^{18} \mathrm{~F}\right] \mathrm{THK} 5317$ and 
hypometabolism, especially in frontal areas [35]. Investigation of intra-subject correlations revealed that $\left[{ }^{18} \mathrm{~F}\right]$ AV1451 was more closely related to hypometabolism than to the MRI results or amyloid- $\beta$ levels in typical and atypical $\mathrm{AD}$, with the strength of the correlation positively related to global tau load and age, and thus to disease progression [193]. In AD patients, although no significant increase in $\left[{ }^{18} \mathrm{~F}\right]$ THK5317 binding was noted at the group level over 17 months, $\left[{ }^{18} \mathrm{~F}\right] \mathrm{FDG}$ binding declined in ADrelated regions [121, 194], suggesting a spatiotemporal offset between tau pathology and functional changes, possibly dependent on $\mathrm{AD}$ severity.

The presence of tau in temporoparietal and occipital regions in $\mathrm{CN}$ subjects and $\mathrm{AD}$ patients is associated with colocalized atrophy [47, 62, 195, 196]. Local and distant correlation analyses reported negative associations between tau and MRI results. $\left[{ }^{18} \mathrm{~F}\right] \mathrm{AV} 1451$ binding was most strongly associated with local atrophy in mild AD, suggesting that tau aggregation drives local neurodegeneration [46, 179]. A (nonlocal) correlation was observed between $\left[{ }^{18} \mathrm{~F}\right] \mathrm{AV} 1451$ in the parietal/precuneus area and MTL atrophy [196]. The relationship between local $\left[{ }^{18} \mathrm{~F}\right]$ AV1451 binding and antecedent longitudinal MRI changes was stronger than that between $\left[{ }^{18} \mathrm{~F}\right] \mathrm{AV} 1451$ uptake and cross-sectional MRI in $\mathrm{CN}$ individuals and AD patients [195, 196], suggesting that tau levels are most strongly related to rates of neurodegenerative change. Interestingly, recent findings [197] have shown that decreased hippocampal volume in $\mathrm{CN}$ subjects, an assumed proxy for taumediated neurodegeneration, led to reduced integrity of the hippocampal cingulum bundle; this, in turn, predicted increased tau in the posterior cingulate, as indexed by $\left[{ }^{18} \mathrm{~F}\right] \mathrm{AV} 1451$ binding, and worse memory.

Animal studies have indeed shown the spread of tau pathology via synaptic connections, with this process accompanied by neurodegenerative changes [198, 199]. This effect, however, was specific to amyloid- $\beta$-positive individuals. Together with previous studies $[37,38,50]$ this study provides empirical support for a model in which cognitive decline occurs when tau pathology spreads beyond the MTL into unimodal and polymodal association areas, in the context of elevated cortical amyloid- $\beta$ levels [200].

Data from studies in traumatic brain injury and stroke have shown that both are accompanied by a transient yet marked increase in t-tau, with no change in p-tau, with t-tau levels correlating with the severity of neuronal injury [201, 202]. Moreover, in Creutzfeldt-Jakob disease, a disorder characterized by rapidly progressive neurodegeneration in the absence of PHF tau, t-tau levels are significantly increased, with p-tau showing no or only minor changes [203, 204]. CSF t-tau is thus considered to reflect the intensity of neuronal injury at a given time point [189].
Studies that examined the relationship between $\left[{ }^{18} \mathrm{~F}\right]$ AV1451 binding and t-tau levels [166, 185, 186] showed a moderately strong positive correlation in analyses combining CN individuals and varied patient groups, but findings were mixed among the controls (absent [41, 166] or restricted to temporal $\left[{ }^{18} \mathrm{~F}\right] \mathrm{AV} 1451$ binding) [187]. Among prodromal AD patients, correlations between $\left[{ }^{18} \mathrm{~F}\right]$ AV1451 binding and t-tau levels were restricted to those with transentorhinal Braak stages while more widespread correlations were found in those with AD dementia [166].

In a combined analysis that included both prodromal $\mathrm{AD}$ and $\mathrm{AD}$ dementia patients, $\left[{ }^{11} \mathrm{C}\right] \mathrm{THK} 5351$ binding in the parahippocampal gyrus was positively correlated with t-tau levels [153]. Though diagnostic performance, based on area under the receiver operating characteristic curve, was similar for t-tau and p-tau levels in $\mathrm{AD}$ patients vs. controls [185],

CSF tau measures were shown, in a related study, to exhibit differing patterns of association to $\left[{ }^{18} \mathrm{~F}\right] \mathrm{AV} 1451$ : while p-tau was associated with tracer retention in temporoparietal areas, $\mathrm{t}$-tau showed the strongest positive correlation with retention of $\left[{ }^{18} \mathrm{~F}\right] \mathrm{AV} 1451$ in prefrontal areas [186], regions known to exhibit tau pathology in more advanced stages of AD [17].

Though preliminary given the modest sample size, this finding was interpreted as supporting the idea that elevated $\mathrm{t}$-tau levels are a marker of tau pathology-driven neurodegeneration. Ultimately, longitudinal studies in larger cohorts incorporating serial biomarkers (CSF and imaging) in individuals across the $\mathrm{AD}$ continuum will be required to properly address this question. As with p-tau and tau PET, however, future studies will need to address the interchangeability of binarized t-tau in comparison to other established measures of neurodegeneration.

Overall, the accumulation of data from studies comparing tau PET with neurodegeneration markers has provided evidence that tau PET is more closely related to neurodegeneration biomarkers (especially metabolism) than to the presence of amyloid. This knowledge is crucial for understanding which in vivo biomarkers are the most useful for measuring disease progression and which are potentially usable as outcome measures in clinical trials. The observation that tau levels and metabolism are more tightly correlated at later disease stages is also important for elucidating the disease stage at which the different biomarkers may be interchangeable. Longitudinal studies are still relatively limited, and it is critical that more longitudinal data are obtained to elucidate the effects of different tau regional distributions on downstream neurodegeneration and cognitive decline.

Cognitive measures Previous research has shown an association between postmortem tau levels (NFTs, as well 
as more varied conformations, e.g., threads) and cognition $[133,205,206]$. A large number of in vivo studies have indicated that the binding of the first-generation tau tracers (THK family, $\left[{ }^{18} \mathrm{~F}\right] \mathrm{AV} 1451,\left[{ }^{11} \mathrm{C}\right] \mathrm{PBB} 3$ ), in contrast to the binding of amyloid- $\beta$ tracers, is associated with different cognitive measures in patients with prodromal or dementiastage $\mathrm{AD}$, in agreement with the available postmortem studies [40, 42, 44, 50, 59, 153, 166, 183, 184, 207, 208]. More importantly, performance in episodic memory tests has been associated with tracer binding loads in the temporal lobe, whereas performance in executive or global cognitive function tests was associated with binding in more widespread neocortical areas [40, 44, 183, 184, 207], a finding to be expected based on the hypothesized neuroanatomical underpinnings of specific cognitive domains. Tau tracer binding has also been associated with poorer outcomes in tests evaluating visuospatial or semantic memory, attention, language, etc. [44, 183, 208, 209]. Furthermore, declines in episodic memory performance over time appear to be associated to some extent with increases in $\left[{ }^{18} \mathrm{~F}\right]$ THK5317 binding in the only longitudinal tau study so far examining such relationships [69]. Interestingly, there could be a relationship between $\left[{ }^{18} \mathrm{~F}\right] \mathrm{AV} 1451$ binding in the MTL and episodic memory performance, even in CN individuals [37, 48, 210], since underlying tau pathology might be present in these individuals, as there was subjective evidence of cognitive impairment [211].

Overall, studies have given evidence that tau is associated to global cognition as well as episodic memory. This relationship seems less strong than between metabolism and cognition, with several studies indicating that neurodegeneration mediates the effect of tau on cognition [183, 184]. The combination of these findings adds support to the proposed hypothetical sequence for the development of $\mathrm{AD}$, namely the presence of amyloid- $\beta$, followed by tau, decreased metabolism, increased atrophy and cognitive decline. Less known, however, is the relationship between tau and cognition in normal aging, which suggests that the mere presence of tau (i.e., in common age-related entorhinal tauopathy) is not sufficient to cause cognitive changes [191].

Methodological aspects of tau PET quantification Several tau PET studies have replicated a quantification method based on the Braak stages [37, 39, 45], but most studies use standard region-of-interest quantification. While the number of longitudinal studies is few, a recent follow-up of a large patient cohort noted that amyloid- $\beta$-positive $\mathrm{CN}$ individuals had showed positive neocortical tau rates beyond the expected Braak stage I/II, suggesting that tau distribution is not strictly limited to the Braak model. The authors concluded that reliable detection of within-person tau accumulation may be obtainable from simple meta-regions of interest, varying from areas showing early (posterior cingulate) and late (orbitofrontal) changes in $\mathrm{AD}$, to temporal and whole brain [70]. A similar observation was made in a separate cohort [63], where elevated tau seemed to accumulate system-wide in patterns somewhat different from the expected Braak progression. These recent observations, if confirmed in future studies with postmortem validation, challenge the view that the topography of tau is more relevant to understand disease progression than a measure of global tau load [212, 213], a finding that has important clinical implications, especially in the field of clinical trials. Braak staging, and the measurement of global or regionspecific tau levels, have also been shown to give similarly accurate diagnoses; however, although the whole-brain tau PET method may be an adequate AD biomarker, more localized methods in $\mathrm{AD}$-vulnerable regions might increase sensitivity to early tau [214].

In contrast to a priori regionally based measures, several studies have explored data-driven methods; these include independent component analysis [38, 63, 215], cluster analyses [176, 216], hierarchical clustering [177], and graph theory [46, 181]. A cluster analysis [176] identified regions (entorhinal, amygdala, occipital, and temporal) that were most informative in discriminating between low- and high$\left[{ }^{18} \mathrm{~F}\right] \mathrm{AV} 1451$ binding in CN participants. Another clustering approach [216] identified distinct patterns of entorhinal vs. neocortical $\left[{ }^{18} \mathrm{~F}\right] \mathrm{AV} 1451$ binding that best explained the age and phenotypical variability of typical and atypical AD patients. Further data-driven methods in new studies with second-generation tracers will be of great value for acquiring more precise knowledge of tau distribution patterns in relation to those of other biomarkers.

In summary, diverse quantification methods have been developed and applied so far in different cohorts, with sometimes conflicting results. In particular, there is accumulating evidence that the topography of tau deposition does not always follow the Braak staging scheme. Thus, other quantification methods have been applied using either a priori ROIs or data-driven approaches. Given the mentioned limited knowledge as to what individual regions may be most sensitive to early tau deposition, further studies using data-driven methods will be of great value, as these can reveal disease-specific patterns of tau deposition without any a priori assumption as to its topography. The use of highly selective second-generation tracers should facilitate the acquisition of more precise knowledge of tau distribution patterns in relation to those of other biomarkers. Finally, few studies have attempted to compare results using different quantification methods [214]; thus future studies comparing these approaches in the same cohort, as well as ante-/post-mortem comparisons, will help validate these different quantification methods, potentially leading to revised in vivo staging schemes for tau. 


\section{Future directions}

\section{Temporal evolution of tau in relation to other biomarkers}

Using diverse quantification methods, including data-driven approaches, new knowledge on the distribution of tau in relation to other biomarkers has been gained. While it cannot be ruled out that amyloid- $\beta$ and tau pathology arise as a result of shared or independent upstream mechanisms (e.g., age or genetic related abnormalities in amyloid- $\beta$ turnover/clearance [217, 218], or cardiac and metabolic conditions [219]), the evidence so far lends support to the modified amyloid- $\beta$ cascade pathway, whereby amyloidosis precedes the spread of pathologic tau, which in turn causes neurodegeneration and cognitive decline $[154,172]$. As mentioned, however, elevated amyloid- $\beta$ and tau hyperphosphorylation may arise independently and subsequently interact in a synergistic fashion [220-223]. Specifically, it has been proposed that tau pathology may precede amyloid- $\beta$ in subcortical and MTL areas, with cortical amyloid- $\beta$ subsequently mediating the extra-temporal spread of tau [171], a model for which preliminary in vivo data is supportive [46, 224]. In either case, tau imaging will prove crucial to clarify the link and temporal lag between amyloid- $\beta$, tau, and neurodegeneration, and how the latter processes in particular relate to cognitive impairment.

\section{Are we ready for clinical trials with tau PET?}

The various stages in the maturation of tau pathology offer targets for intervention; these range from inhibiting the expression of tau itself $[225,226]$, to preventing posttranslational modifications [227, 228] and tau aggregation [229, 230]. At present, however, most anti-tau clinical trials involve tau immunotherapy [231]. Beyond its use for patient selection and proof of target engagement [178], tau PET may prove valuable as an outcome measure [232]. In the largest longitudinal analysis performed to date on tau PET [70, 233], significant tau accumulation was shown over 1 year in clinically unimpaired amyloid$\beta$-positive individuals, specifically, in regions shown to be the earliest sites of amyloid- $\beta$ accumulation [234]. Although much validation work remains, including optimization and standardization of methodological aspects, findings from this study suggest that tau PET may be suitable for incorporation into clinical trials with individuals across the spectrum of AD [233]. Given the likely need for combinatorial approaches combining both anti-tau and anti-amyloid- $\beta$ approaches [178], additional longitudinal studies are needed to elucidate the time lag between amyloid- $\beta$ and tau deposition to better understand the optimal starting point for such therapies [235].

\section{Potential applications of tau PET}

The fast-developing research on tau PET over the past few years has promoted discussion on its usefulness for the diagnosis of neurodegenerative diseases. Although the evidence so far indicates that the currently available tracers consistently bind to PHF AD-type tau, with variable results when it comes to binding in non-AD tauopathies, tau PET seems to be a promising tool for the differential diagnosis of different tauopathies and in the work-up of atypical AD phenotypes that are difficult to diagnose. Given the seemingly reduced off-target striatal retention of secondgeneration compounds, studies using these ligands are likely to prove of value in the characterization of these disorders, if the tracers bind to non-AD tau-positive deposits. Studies addressing the clinical impact of tau imaging in terms of its ability to help resolve diagnostically uncertain cases, for instance, and its use in comparison to and with other established biomarkers, are critical [236]. Whether a subset of tracers will ultimately prove interchangeable, however, similar to amyloid- $\beta$ ligands, or whether varied compounds will be required to cover the spectrum of tauopathies, remains an open question. More broadly, it is also expected that tau imaging could help with disease staging and to address unanswered questions pertaining to how amyloid- $\beta$ and tau, both independently and via synergistic interactions, result in cognitive decline, and their relationships with other pathologies such as TDP-43 and $\alpha$-synuclein, when tracers for these targets become available.

Acknowledgements The authors wish to thank the following individuals for providing images or the chemical structures of secondgeneration tau ligands as well as $\left[{ }^{18} \mathrm{~F}\right] \mathrm{AV} 1451$ images from non-AD patients: Drs. Ruben Smith and Oskar Hansson (Lund University, Sweden); Drs. Andrew Stephens and Mathias Berndt (Piramal Imaging $\mathrm{GmbH}$, Berlin, Germany), Drs. Vincent Doré, Victor Villemagne, and Christopher Rowe (Centre for PET, Austin Health, Heidelberg, and University of Melbourne, Victoria, Australia); Drs. James Rowe and Simon P. Jones (Cambridge, UK) and Dr. Chul Hyoung Lyoo (Yonsei University College of Medicine, Seoul, South Korea). The authors wish also to thank Dr. Ezio Giacobini (University of Geneva, Geneva, Switzerland) for his valuable and insightful comments. The authors wish to thank the Swedish Foundation for Strategic Research (SSF), the Swedish Research Council (projects 05817, 02695, and 06086), the Regional Agreement on Medical Training and Clinical Research (ALF) for Stockholm County Council, the Foundation for Old Servants, Axel Linder's Foundation, Gun and Bertil Stohne's Foundation, the KI Foundations, the Swedish Brain Foundation, the Swedish Alzheimer's Foundation, Swedish Dementia Association, the Åke Wiberg Foundation, and the EU FW7 large-scale integrating project INMiND (http://www.uni-muenster.de/INMiND) for financial support.

Author contributions Review of the literature and drafting of the manuscript were divided among co-authors. Display figures were drafted by $\mathrm{KC}, \mathrm{AL}$, and LL. AN oversaw the project, providing feedback and guidance throughout the writing process. All authors reviewed the final manuscript. 


\section{Compliance with ethical standards}

Conflict of interest The authors declare that they have no conflict of interest.

Publisher's note: Springer Nature remains neutral with regard to jurisdictional claims in published maps and institutional affiliations.

Open Access This article is licensed under a Creative Commons Attribution 4.0 International License, which permits use, sharing, adaptation, distribution and reproduction in any medium or format, as long as you give appropriate credit to the original author(s) and the source, provide a link to the Creative Commons license, and indicate if changes were made. The images or other third party material in this article are included in the article's Creative Commons license, unless indicated otherwise in a credit line to the material. If material is not included in the article's Creative Commons license and your intended use is not permitted by statutory regulation or exceeds the permitted use, you will need to obtain permission directly from the copyright holder. To view a copy of this license, visit http://creativecommons. org/licenses/by/4.0/.

\section{References}

1. Buee L, Bussiere T, Buee-Scherrer V, Delacourte A, Hof PR. Tau protein isoforms, phosphorylation and role in neurodegenerative disorders. Brain Res Brain Res Rev. 2000; 33:95-130.

2. Maas T, Eidenmuller J, Brandt R. Interaction of tau with the neural membrane cortex is regulated by phosphorylation at sites that are modified in paired helical filaments. J Biol Chem. 2000;275:15733-40.

3. Hernandez F, Avila J. Tauopathies. Cell Mol Life Sci. 2007;64:2219-33.

4. Arima K. Ultrastructural characteristics of tau filaments in tauopathies: immuno-electron microscopic demonstration of tau filaments in tauopathies. Neuropathology. 2006;26:475-83.

5. Martin L, Latypova X, Terro F. Post-translational modifications of tau protein: implications for Alzheimer's disease. Neurochem Int. 2011;58:458-71.

6. Delacourte A. Tauopathies: recent insights into old diseases. Folia Neuropathol. 2005;43:244-57.

7. Delacourte A, Buee L. Tau pathology: a marker of neurodegenerative disorders. Curr Opin Neurol. 2000;13:371-6.

8. Xu S, Brunden KR, Trojanowski JQ, Lee VM. Characterization of tau fibrillization in vitro. Alzheimers Dement. 2010;6:110-7.

9. Liu F, Gong CX. Tau exon 10 alternative splicing and tauopathies. Mol Neurodegener. 2008;3:8.

10. Wang JZ, Grundke-Iqbal I, Iqbal K. Kinases and phosphatases and tau sites involved in Alzheimer neurofibrillary degeneration. Eur J Neurosci. 2007;25:59-68.

11. Qiu L, Ng G, Tan EK, Liao P, Kandiah N, Zeng L. Chronic cerebral hypoperfusion enhances Tau hyperphosphorylation and reduces autophagy in Alzheimer's disease mice. Sci Rep. 2016;6:23964.

12. Katsinelos T, Zeitler M, Dimou E, Karakatsani A, Muller HM, Nachman E, et al. Unconventional secretion mediates the transcellular spreading of tau. Cell Rep. 2018;23:2039-55.

13. Polanco JC, Scicluna BJ, Hill AF, Gotz J. Extracellular vesicles isolated from the brains of $\mathrm{rTg} 4510$ mice seed tau protein aggregation in a threshold-dependent manner. J Biol Chem. 2016;291:12445-66.
14. Wang Y, Balaji V, Kaniyappan S, Kruger L, Irsen S, Tepper K, et al. The release and trans-synaptic transmission of tau via exosomes. Mol Neurodegener. 2017;12:5.

15. Wu JW, Hussaini SA, Bastille IM, Rodriguez GA, Mrejeru A, Rilett K, et al. Neuronal activity enhances tau propagation and tau pathology in vivo. Nat Neurosci. 2016;19:1085-92.

16. Braak H, Braak E. Frequency of stages of Alzheimer-related lesions in different age categories. Neurobiol Aging. 1997; 18:351-7.

17. Delacourte A, David JP, Sergeant N, Buee L, Wattez A, Vermersch $\mathrm{P}$, et al. The biochemical pathway of neurofibrillary degeneration in aging and Alzheimer's disease. Neurology. 1999;52:1158-65.

18. Williams DR, Holton JL, Strand C, Pittman A, de Silva R, Lees $\mathrm{AJ}$, et al. Pathological tau burden and distribution distinguishes progressive supranuclear Palsy-Parkinsonism from Richardson's syndrome. Brain. 2007;130(Pt 6):1566-76.

19. Forman MS, Zhukareva V, Bergeron C, Chin SS, Grossman M, Clark C, et al. Signature tau neuropathology in gray and white matter of corticobasal degeneration. Am J Pathol. 2002;160:2045-53.

20. Kouri N, Murray ME, Hassan A, Rademakers R, Uitti RJ, Boeve $\mathrm{BF}$, et al. Neuropathological features of corticobasal degeneration presenting as corticobasal syndrome or Richardson syndrome. Brain. 2011;134(Pt 11):3264-75.

21. Ling H, Kovacs GG, Vonsattel JP, Davey K, Mok KY, Hardy J, et al. Astrogliopathy predominates the earliest stage of corticobasal degeneration pathology. Brain. 2016;139(Pt 12):3237-52.

22. Villemagne VL, Okamura N. In vivo tau imaging: obstacles and progress. Alzheimers Dement. 2014;10(3 Suppl):S254-264.

23. Robertson JS, Rowe CC, Villemagne VL. Tau imaging with PET: an overview of challenges, current progress, and future applications. Q J Nucl Med Mol Imaging. 2017;61:405-13.

24. Thompson PW, Ye L, Morgenstern JL, Sue L, Beach TG, Judd DJ, et al. Interaction of the amyloid imaging tracer FDDNP with hallmark Alzheimer's disease pathologies. J Neurochem. 2009;109:623-30.

25. Chien DT, Bahri S, Szardenings AK, Walsh JC, Mu F, Su MY, et al. Early clinical PET imaging results with the novel PHF-tau radioligand [F-18]-T807. J Alzheimers Dis. 2013;34:457-68.

26. Maruyama M, Shimada H, Suhara T, Shinotoh H, Ji B, Maeda J, et al. Imaging of tau pathology in a tauopathy mouse model and in Alzheimer patients compared to normal controls. Neuron. 2013;79:1094-108.

27. Walji AM, Hostetler ED, Selnick H, Zeng Z, Miller P, Bennacef I, et al. Discovery of 6-(Fluoro-(18)F)-3-(1H-pyrrolo[2,3-c]pyridin-1-yl)isoquinolin-5-amine ([(18)F]-MK-6240): a positron emission tomography (PET) imaging agent for quantification of neurofibrillary tangles (NFTs). J Med Chem. 2016;59:4778-89.

28. Fawaz MV, Brooks AF, Rodnick ME, Carpenter GM, Shao X, Desmond TJ, et al. High affinity radiopharmaceuticals based upon lansoprazole for PET imaging of aggregated tau in Alzheimer's disease and progressive supranuclear palsy: synthesis, preclinical evaluation, and lead selection. ACS Chem Neurosci. 2014;5:718-30.

29. Gobbi LC, Knust H, Korner M, Honer M, Czech C, Belli S, et al. Identification of three novel radiotracers for imaging aggregated tau in alzheimer's disease with positron emission tomography. J Med Chem. 2017;60:7350-70.

30. Declercq L, Rombouts F, Koole M, Fierens K, Marien J, Langlois X, et al. Preclinical evaluation of (18)F-JNJ64349311, a novel PET tracer for tau imaging. J Nucl Med. 2017;58:975-81.

31. Sanabria Bohorquez S, Barret O, Tamagnan G, Alagille D, Marik J, Ayalon G, et al. Evaluation of tau burden in a crosssectional cohort of Alzheimer's disease subjects using $\left[{ }^{18} \mathrm{~F}\right] \mathrm{GTP} 1$ (Genentech tau probe 1). Proceedings of the Alzheimer's 
Association International Conference. London, UK: Alzheimer's \& Dementia; 2017;12:P1172.

32. Saint-Aubert L, Lemoine L, Chiotis K, Leuzy A, RodriguezVieitez E, Nordberg A. Tau PET imaging: present and future directions. Mol Neurodegener. 2017;12:19.

33. Ono M, Sahara N, Kumata K, Ji B, Ni R, Koga S, et al. Distinct binding of PET ligands PBB3 and AV-1451 to tau fibril strains in neurodegenerative tauopathies. Brain. 2017;140:764-80.

34. Wren MC, Lashley T, Arstad E, Sander K. Large inter- and intracase variability of first generation tau PET ligand binding in neurodegenerative dementias. Acta Neuropathol Commun. 2018;6:34.

35. Chiotis K, Saint-Aubert L, Savitcheva I, Jelic V, Andersen P, Jonasson M, et al. Imaging in-vivo tau pathology in Alzheimer's disease with THK5317 PET in a multimodal paradigm. Eur J Nucl Med Mol Imaging. 2016;43:1686-99.

36. Lockhart SN, Baker SL, Okamura N, Furukawa K, Ishiki A, Furumoto S, et al. Dynamic PET measures of tau accumulation in cognitively normal older adults and Alzheimer's disease patients measured using [18F] THK-5351. PLoS ONE. 2016;11: $\mathrm{e} 0158460$.

37. Scholl M, Lockhart SN, Schonhaut DR, O'Neil JP, Janabi M, Ossenkoppele R, et al. PET Imaging of tau deposition in the aging human brain. Neuron. 2016;89:971-82.

38. Brier MR, Gordon B, Friedrichsen K, McCarthy J, Stern A, Christensen J, et al. Tau and abeta imaging, CSF measures, and cognition in Alzheimer's disease. Sci Transl Med. 2016;8:338ra366.

39. Cho H, Choi JY, Hwang MS, Kim YJ, Lee HM, Lee HS, et al. In vivo cortical spreading pattern of tau and amyloid in the Alzheimer disease spectrum. Ann Neurol. 2016;80:247-58.

40. Cho H, Choi JY, Hwang MS, Lee JH, Kim YJ, Lee HM, et al. Tau PET in Alzheimer disease and mild cognitive impairment. Neurology. 2016;87:375-83.

41. Gordon BA, Friedrichsen K, Brier M, Blazey T, Su Y, Christensen $\mathrm{J}$, et al. The relationship between cerebrospinal fluid markers of Alzheimer pathology and positron emission tomography tau imaging. Brain. 2016;139(Pt 8):2249-60.

42. Johnson KA, Schultz A, Betensky RA, Becker JA, Sepulcre J, Rentz D, et al. Tau positron emission tomographic imaging in aging and early Alzheimer disease. Ann Neurol. 2016;79:110-9.

43. Mormino EC, Papp KV, Rentz DM, Schultz AP, LaPoint M, Amariglio R, et al. Heterogeneity in suspected non-alzheimer disease pathophysiology among clinically normal older individuals. JAMA Neurol. 2016;73:1185-91.

44. Ossenkoppele R, Schonhaut DR, Scholl M, Lockhart SN, Ayakta $\mathrm{N}$, Baker SL, et al. Tau PET patterns mirror clinical and neuroanatomical variability in Alzheimer's disease. Brain. 2016;139 (Pt 5):1551-67.

45. Schwarz AJ, Yu P, Miller BB, Shcherbinin S, Dickson J, Navitsky M, et al. Regional profiles of the candidate tau PET ligand 18F-AV-1451 recapitulate key features of Braak histopathological stages. Brain. 2016;139(Pt 5):1539-50.

46. Sepulcre J, Schultz AP, Sabuncu M, Gomez-Isla T, Chhatwal J, Becker A, et al. In vivo tau, amyloid, and gray matter profiles in the aging brain. J Neurosci. 2016;36:7364-74.

47. Wang L, Benzinger TL, Su Y, Christensen J, Friedrichsen K, Aldea $\mathrm{P}$, et al. Evaluation of tau imaging in staging Alzheimer disease and revealing interactions between beta-amyloid and tauopathy. JAMA Neurol. 2016;73:1070-7.

48. Rentz DM, Mormino EC, Papp KV, Betensky RA, Sperling RA, Johnson KA. Cognitive resilience in clinical and preclinical Alzheimer's disease: the Association of Amyloid and Tau Burden on cognitive performance. Brain Imaging Behav. 2017;11:383-90.

49. Vemuri P, Lowe VJ, Knopman DS, Senjem ML, Kemp BJ, Schwarz CG, et al. Tau-PET uptake: regional variation in average SUVR and impact of amyloid deposition. Alzheimers Dement (Amst). 2017;6:21-30.

50. Pontecorvo MJ, Devous MD, Navitsky M, Lu M, Salloway S, Schaerf FW, et al. Relationships between flortaucipir PET tau binding and amyloid burden, clinical diagnosis, age and cognition. Brain. 2017;140:748-63.

51. Braak H, Thal DR, Ghebremedhin E, Del Tredici K. Stages of the pathologic process in Alzheimer disease: age categories from 1 to 100 years. J Neuropathol Exp Neurol. 2011;70:960-9.

52. Tomlinson BE, Blessed G, Roth M. Observations on the brains of demented old people. J Neurol Sci. 1970;11:205-42.

53. Crary JF, Trojanowski JQ, Schneider JA, Abisambra JF, Abner EL, Alafuzoff I, et al. Primary age-related tauopathy (PART): a common pathology associated with human aging. Acta Neuropathol. 2014;128:755-66.

54. Jack CR. PART and SNAP. Acta Neuropathol. 2014;128:773-6.

55. Duyckaerts C, Braak H, Brion JP, Buee L, Del Tredici K, Goedert M, et al. PART is part of Alzheimer disease. Acta Neuropathol. 2015;129:749-56.

56. Jellinger KA, Alafuzoff I, Attems J, Beach TG, Cairns NJ, Crary $\mathrm{JF}$, et al. PART, a distinct tauopathy, different from classical sporadic Alzheimer disease. Acta Neuropathol. 2015;129:75762.

57. Jack CR, Holtzman DM. Biomarker modeling of Alzheimer's disease. Neuron. 2013;80:1347-58.

58. Josephs KA, Murray ME, Tosakulwong N, Whitwell JL, Knopman DS, Machulda MM, et al. Tau aggregation influences cognition and hippocampal atrophy in the absence of betaamyloid: a clinico-imaging-pathological study of primary agerelated tauopathy (PART). Acta Neuropathol. 2017;133:705-15.

59. Harada R, Okamura N, Furumoto S, Furukawa K, Ishiki A, Tomita N, et al. [(18)F]THK-5117 PET for assessing neurofibrillary pathology in Alzheimer's disease. Eur J Nucl Med Mol Imaging. 2015;42:1052-61.

60. Braak H, Braak E. Neuropathological stageing of Alzheimerrelated changes. Acta Neuropathol. 1991;82:239-59.

61. Ossenkoppele R, Rabinovici G, Smith R, Cho H, Schöll M, Strandberg O, et al. Discriminative accuracy of [18F]flortaucipir positron emission tomography for Alzheimer disease vs. other neurodegenerative disorders. JAMA Neurol. 2018;320:1151-62.

62. Xia C, Makaretz SJ, Caso C, McGinnis S, Gomperts SN, Sepulcre J, et al. Association of in vivo [18F]AV-1451 tau PET imaging results with cortical atrophy and symptoms in typical and atypical Alzheimer disease. JAMA Neurol. 2017;74:427-36.

63. Jones DT, Graff-Radford J, Lowe VJ, Wiste HJ, Gunter JL, Senjem ML, et al. Tau, amyloid, and cascading network failure across the Alzheimer's disease spectrum. Cortex. 2017;97: 143-59.

64. Phillips JS, Das SR, McMillan CT, Irwin DJ, Roll EE, Da Re F, et al. Tau PET imaging predicts cognition in atypical variants of Alzheimer's disease. Hum Brain Mapp. 2018;39:691-708.

65. Dronse J, Fliessbach K, Bischof GN, von Reutern B, Faber J, Hammes J, et al. In vivo patterns of tau pathology, amyloid-beta burden, and neuronal dysfunction in clinical variants of Alzheimer's disease. J Alzheimers Dis. 2017;55:465-71.

66. Ossenkoppele R, Cohn-Sheehy BI, La Joie R, Vogel JW, Moller $\mathrm{C}$, Lehmann $\mathrm{M}$, et al. Atrophy patterns in early clinical stages across distinct phenotypes of Alzheimer's disease. Hum Brain Mapp. 2015;36:4421-37.

67. Ossenkoppele R, Schonhaut DR, Baker SL, O’Neil JP, Janabi M, Ghosh PM, et al. Tau, amyloid, and hypometabolism in a patient with posterior cortical atrophy. Ann Neurol. 2015;77:338-42.

68. Southekal S, Devous MD, Kennedy I, Navitsky M, Lu M, Joshi $\mathrm{AD}$, et al. Flortaucipir $\mathrm{F} 18$ quantitation using a parametric estimate of reference signal intensity (PERSI). J Nucl Med. 2018;59:944-51. 
69. Chiotis K, Saint-Aubert L, Rodriguez-Vieitez E, Leuzy A, Almkvist O, Savitcheva I, et al. Longitudinal changes of tau PET imaging in relation to hypometabolism in prodromal and Alzheimer's disease dementia. Mol Psychiatry. 2018;23:1666-73.

70. Jack CR Jr., Wiste HJ, Schwarz CG, Lowe VJ, Senjem ML, Vemuri P, et al. Longitudinal tau PET in ageing and Alzheimer's disease. Brain. 2018;141:1517-28.

71. Ishiki A, Okamura N, Furukawa K, Furumoto S, Harada R, Tomita $\mathrm{N}$, et al. Longitudinal assessment of tau pathology in patients with Alzheimer's disease using [18F]THK-5117 positron emission tomography. PLoS ONE. 2015;10:e140311.

72. Wong DF, Comley RA, Kuwabara H, Rosenberg PB, Resnick SM, Ostrowitzki, et al. Characterization of 3 Novel Tau Radiopharmaceuticals, (11)C-RO-963, (11)C-RO-643, and (18)F-RO948, in Healthy Controls and in Alzheimer Subjects. J Nucl Med. 2018;59:1869-76.

73. Betthauser TJ, Cody KA, Zammit MD, Murali D, Converse AK, Barnhart TE, et al. In vivo characterization and quantification of neurofibrillary tau PET radioligand [(18)F]MK-6240 in humans from Alzheimer's disease dementia to young controls. J Nucl Med. 2018. pii: jnumed.118.209650. https://doi.org/10.2967/ jnumed.118.209650. [Epub ahead of print]

74. Lohith TG, Bennacef I, Vandenberghe R, Vandenbulcke M, Salinas-Valenzuela C, Declercq R, et al. First-in-human brain imaging of Alzheimer dementia patients and elderly controls with (18)F-MK-6240, a PET tracer targeting neurofibrillary tangle pathology. J Nucl Med. 2018. pii: jnumed.118.208215. https://doi.org/10.2967/jnumed.118. 208215. [Epub ahead of print]

75. Lebouvier T, Pasquier F, Buee L. Update on tauopathies. Curr Opin Neurol. 2017;30:589-98.

76. Armstrong MJ, Litvan I, Lang AE, Bak TH, Bhatia KP, Borroni $\mathrm{B}$, et al. Criteria for the diagnosis of corticobasal degeneration. Neurology. 2013;80:496-503.

77. Hoglinger GU, Respondek G, Stamelou M, Kurz C, Josephs KA, Lang $\mathrm{AE}$, et al. Clinical diagnosis of progressive supranuclear palsy: the movement disorder society criteria. Mov Disord. 2017;32:853-64.

78. Kikuchi A, Okamura N, Hasegawa T, Harada R, Watanuki S, Funaki $\mathrm{Y}$, et al. In vivo visualization of tau deposits in corticobasal syndrome by 18F-THK5351 PET. Neurology. 2016;87:2309-16

79. Smith R, Scholl M, Widner H, van Westen D, Svenningsson P, Hagerstrom D, et al. In vivo retention of (18)F-AV-1451 in corticobasal syndrome. Neurology. 2017;89:845-53.

80. Cho H, Baek MS, Choi JY, Lee SH, Kim JS, Ryu YH, et al. (18) F-AV-1451 binds to motor-related subcortical gray and white matter in corticobasal syndrome. Neurology. 2017;89:1170-8.

81. Schonhaut DR, McMillan CT, Spina S, Dickerson BC, Siderowf A, Devous MD, et al. (18) F-flortaucipir tau positron emission tomography distinguishes established progressive supranuclear palsy from controls and Parkinson disease: a multicenter study. Ann Neurol. 2017;82:622-34.

82. Passamonti L, Vazquez Rodriguez P, Hong YT, Allinson KS, Williamson D, Borchert RJ, et al. 18F-AV-1451 positron emission tomography in Alzheimer's disease and progressive supranuclear palsy. Brain. 2017;140:781-91.

83. Cho H, Choi JY, Hwang MS, Lee SH, Ryu YH, Lee MS, et al. Subcortical (18) F-AV-1451 binding patterns in progressive supranuclear palsy. Mov Disord. 2017;32:134-40.

84. Smith R, Schain M, Nilsson C, Strandberg O, Olsson T, Hagerstrom D, et al. Increased basal ganglia binding of (18) FAV-1451 in patients with progressive supranuclear palsy. Mov Disord. 2017;32:108-14.

85. Hammes J, Bischof GN, Giehl K, Faber J, Drzezga A, Klockgether $\mathrm{T}$, et al. Elevated in vivo [18F]-AV-1451 uptake in a patient with progressive supranuclear palsy. Mov Disord. 2017;32:170-1.

86. Brendel M, Schonecker S, Hoglinger G, Lindner S, Havla J, Blautzik J, et al. [(18)F]-THK5351 PET correlates with topology and symptom severity in progressive supranuclear palsy. Front Aging Neurosci. 2017;9:440.

87. Josephs KA, Dickson DW. Diagnostic accuracy of progressive supranuclear palsy in the Society for progressive supranuclear palsy brain bank. Mov Disord. 2003;18:1018-26.

88. Niccolini F, Wilson H, Hirschbichler S, Yousaf T, Pagano G, Whittington A, et al. Disease-related patterns of in vivo pathology in Corticobasal syndrome. Eur J Nucl Med Mol Imaging. 2018;45:2413-25.

89. Coakeley S, Cho SS, Koshimori Y, Rusjan P, Harris M, Ghadery $\mathrm{C}$, et al. Positron emission tomography imaging of tau pathology in progressive supranuclear palsy. J Cereb Blood Flow Metab. 2017;37:3150-60.

90. McMillan CT, Irwin DJ, Nasrallah I, Phillips JS, Spindler M, Rascovsky K, et al. Multimodal evaluation demonstrates in vivo (18)F-AV-1451 uptake in autopsy-confirmed corticobasal degeneration. Acta Neuropathol. 2016;132:935-7.

91. Whitwell JL, Lowe VJ, Tosakulwong N, Weigand SD, Senjem ML, Schwarz CG, et al. [(18) F]AV-1451 tau positron emission tomography in progressive supranuclear palsy. Mov Disord. 2017;32:124-33.

92. McKee AC, Stern RA, Nowinski CJ, Stein TD, Alvarez VE, Daneshvar DH, et al. The spectrum of disease in chronic traumatic encephalopathy. Brain. 2013;136(Pt 1):43-64.

93. Mitsis EM, Riggio S, Kostakoglu L, Dickstein DL, Machac J, Delman B, et al. Tauopathy PET and amyloid PET in the diagnosis of chronic traumatic encephalopathies: studies of a retired NFL player and of a man with FTD and a severe head injury. Transl Psychiatry. 2014;4:e441.

94. Dickstein DL, Pullman MY, Fernandez C, Short JA, Kostakoglu L, Knesaurek K, et al. Cerebral [(18) F]T807/AV1451 retention pattern in clinically probable CTE resembles pathognomonic distribution of CTE tauopathy. Transl Psychiatry. 2016;6:e900.

95. Jellinger KA, Attems J. Prevalence and impact of vascular and Alzheimer pathologies in Lewy body disease. Acta Neuropathol. 2008;115:427-36.

96. Jellinger KA, Seppi K, Wenning GK, Poewe W. Impact of coexistent Alzheimer pathology on the natural history of Parkinson's disease. J Neural Transm (Vienna). 2002;109:329-39.

97. Flament S, Delacourte A, Mann DM. Phosphorylation of tau proteins: a major event during the process of neurofibrillary degeneration. A comparative study between Alzheimer's disease and Down's syndrome. Brain Res. 1990;516:15-19.

98. Howlett DR, Whitfield D, Johnson M, Attems J, O'Brien JT, Aarsland D, et al. Regional multiple pathology scores are associated with cognitive decline in lewy body dementias. Brain Pathol. 2015;25:401-8.

99. Rafii MS, Lukic AS, Andrews RD, Brewer J, Rissman RA, Strother SC, et al. PET imaging of tau pathology and relationship to amyloid, longitudinal MRI, and cognitive change in down syndrome: results from the down syndrome biomarker initiative (DSBI). J Alzheimers Dis. 2017;60:439-50.

100. Lee SH, Cho H, Choi JY, Lee JH, Ryu YH, Lee MS, et al. Distinct patterns of amyloid-dependent tau accumulation in Lewy body diseases. Mov Disord. 2018;33:262-72.

101. Winer JR, Maass A, Pressman P, Stiver J, Schonhaut DR, Baker SL, et al. Associations between tau, beta-amyloid, and cognition in Parkinson disease. JAMA Neurol. 2018;75:227-35.

102. Kantarci K, Lowe VJ, Boeve BF, Senjem ML, Tosakulwong N, Lesnick TG, et al. AV-1451 tau and beta-amyloid positron emission tomography imaging in dementia with Lewy bodies. Ann Neurol. 2017;81:58-67. 
103. Gomperts SN, Locascio JJ, Makaretz SJ, Schultz A, Caso C, Vasdev N, et al. Tau positron emission tomographic imaging in the Lewy body diseases. JAMA Neurol. 2016;73:1334-41.

104. Hansen AK, Knudsen K, Lillethorup TP, Landau AM, Parbo P, Fedorova T, et al. In vivo imaging of neuromelanin in Parkinson's disease using 18F-AV-1451 PET. Brain. 2016;139(Pt 7):2039-49.

105. Smith R, Scholl M, Londos E, Ohlsson T, Hansson O. (18)FAV-1451 in Parkinson's disease with and without dementia and in Dementia with Lewy bodies. Sci Rep. 2018;8:4717.

106. Goris A, Williams-Gray CH, Clark GR, Foltynie T, Lewis SJ, Brown J, et al. Tau and alpha-synuclein in susceptibility to, and dementia in, Parkinson's disease. Ann Neurol. 2007;62:145-53.

107. Merdes AR, Hansen LA, Jeste DV, Galasko D, Hofstetter CR, Ho GJ, et al. Influence of Alzheimer pathology on clinical diagnostic accuracy in dementia with Lewy bodies. Neurology. 2003;60:1586-90.

108. Clinton LK, Blurton-Jones M, Myczek K, Trojanowski JQ, LaFerla FM. Synergistic interactions between Abeta, tau, and alpha-synuclein: acceleration of neuropathology and cognitive decline. J Neurosci. 2010;30:7281-9.

109. Guo JL, Covell DJ, Daniels JP, Iba M, Stieber A, Zhang B, et al. Distinct alpha-synuclein strains differentially promote tau inclusions in neurons. Cell. 2013;154:103-17.

110. Gearing M, Lynn M, Mirra SS. Neurofibrillary pathology in Alzheimer disease with Lewy bodies: two subgroups. Arch Neurol. 1999;56:203-8.

111. Lowe VJ, Curran G, Fang P, Liesinger AM, Josephs KA, Parisi JE, et al. An autoradiographic evaluation of AV-1451 Tau PET in dementia. Acta Neuropathol Commun. 2016;4:58.

112. Marquie M, Normandin MD, Vanderburg CR, Costantino IM, Bien EA, Rycyna LG, et al. Validating novel tau positron emission tomography tracer [F-18]-AV-1451 (T807) on postmortem brain tissue. Ann Neurol. 2015;78:787-800.

113. Marquie M, Normandin MD, Meltzer AC, Siao Tick Chong M, Andrea NV, Anton-Fernandez A, et al. Pathological correlations of [F-18]-AV-1451 imaging in non-alzheimer tauopathies. Ann Neurol. 2017;81:117-28.

114. Sander K, Lashley T, Gami P, Gendron T, Lythgoe MF, Rohrer JD, et al. Characterization of tau positron emission tomography tracer [(18)F]AV-1451 binding to postmortem tissue in Alzheimer's disease, primary tauopathies, and other dementias. Alzheimers Dement. 2016;12:1116-24.

115. Josephs KA, Whitwell JL, Tacik P, Duffy JR, Senjem ML, Tosakulwong N, et al. [18F]AV-1451 tau-PET uptake does correlate with quantitatively measured 4R-tau burden in autopsy-confirmed corticobasal degeneration. Acta Neuropathol. 2016;132:931-3.

116. Smith R, Scholl M, Honer M, Nilsson CF, Englund E, Hansson O. Tau neuropathology correlates with FDG-PET, but not AV1451-PET, in progressive supranuclear palsy. Acta Neuropathol. 2017;133:149-51.

117. Coakeley S, Ang LC, Jansen GH, Cho SS, Lang AE, Houle S, et al. [(18) F]AV-1451 binding and postmortem pathology of CBD. Mov Disord. 2018;33:1360-1.

118. Harada R, Okamura N, Furumoto S, Tago T, Yanai K, Arai H, et al. Characteristics of Tau and Its Ligands in PET Imaging. Biomolecules. 2016;6:7.

119. Ishiki A, Harada R, Kai H, Sato N, Totsune T, Tomita N, et al. Neuroimaging-pathological correlations of [(18)F]THK5351 PET in progressive supranuclear palsy. Acta Neuropathol Commun. 2018;6:53.

120. Jang YK, Lyoo CH, Park S, Oh SJ, Cho H, Oh M, et al. Head to head comparison of [(18)F] AV-1451 and [(18)F] THK5351 for tau imaging in Alzheimer's disease and frontotemporal dementia. Eur J Nucl Med Mol Imaging. 2018;45:432-42.

121. Chiotis K, Saint-Aubert L, Rodriguez-Vieitez E, Leuzy A, Almkvist O, Savitcheva I, et al. Longitudinal changes of tau PET imaging in relation to hypometabolism in prodromal and Alzheimer's disease dementia. Mol Psychiatry. 2018;23:1666-73.

122. Cole GB, Satyamurthy N, Liu J, Wong KP, Small GW, Huang $\mathrm{SC}$, et al. The value of in vitro binding as predictor of in vivo results: a case for [(18)F]FDDNP PET. Mol Imaging Biol. 2018. https://doi.org/10.1007/s11307-018-1210-2. [Epub ahead of print]

123. Lemoine L, Gillberg PG, Svedberg M, Stepanov V, Jia Z, Huang $\mathrm{J}$, et al. Comparative binding properties of the tau PET tracers THK5117, THK5351, PBB3, and T807 in postmortem Alzheimer brains. Alzheimers Res Ther. 2017;9:96.

124. Harada R, Ishiki A, Kai H, Sato N, Furukawa K, Furumoto S, et al. Correlations of (18)F-THK5351 PET with postmortem burden of tau and astrogliosis in Alzheimer disease. J Nucl Med. 2018;59:671-4.

125. Klunk WE. Molecular imaging: what is right and what is an illusion? Alzheimers Dement. 2018;10:217-20.

126. Hashimoto H, Kawamura K, Igarashi N, Takei M, Fujishiro T, Aihara Y, et al. Radiosynthesis, photoisomerization, biodistribution, and metabolite analysis of 11C-PBB3 as a clinically useful PET probe for imaging of tau pathology. J Nucl Med. 2014;55:1532-8.

127. Hashimoto H, Kawamura K, Takei M, Igarashi N, Fujishiro T, Shiomi S, et al. Identification of a major radiometabolite of [11C] PBB3. Nucl Med Biol. 2015;42:905-10.

128. Jonasson M, Wall A, Chiotis K, Saint-Aubert L, Wilking H, Sprycha M, et al. Tracer kinetic analysis of (S)-18F-THK5117 as a PET tracer for assessing tau pathology. J Nucl Med. 2016;57:574-81.

129. Baker SL, Lockhart SN, Price JC, He M, Huesman RH, Schonhaut D, et al. Reference tissue-based kinetic evaluation of 18F-AV-1451 for tau imaging. J Nucl Med. 2017;58:332-8.

130. Heurling K, Smith R, Strandberg OT, Schain M, Ohlsson T, Hansson $\mathrm{O}$, et al. Regional times to equilibria and their impact on semi-quantification of [(18)F]AV-1451 uptake. J Cereb Blood Flow Metab. 2018: 271678×18791430. https://doi.org/10.1177/ 0271678X18791430. [Epub ahead of print]

131. Jucker M, Walker LC. Self-propagation of pathogenic protein aggregates in neurodegenerative diseases. Nature. 2013;501:4551 .

132. Braskie MN, Klunder AD, Hayashi KM, Protas H, Kepe V, Miller KJ, et al. Plaque and tangle imaging and cognition in normal aging and Alzheimer's disease. Neurobiol Aging. 2010;31:1669-78.

133. Small GW, Kepe V, Ercoli LM, Siddarth P, Bookheimer SY, Miller KJ, et al. PET of brain amyloid and tau in mild cognitive impairment. N Engl J Med. 2006;355:2652-63.

134. Shoghi-Jadid K, Small GW, Agdeppa ED, Kepe V, Ercoli LM, Siddarth $\mathrm{P}$, et al. Localization of neurofibrillary tangles and betaamyloid plaques in the brains of living patients with Alzheimer disease. Am J Geriatr Psychiatry. 2002;10:24-35.

135. Agdeppa ED, Kepe V, Liu J, Flores-Torres S, Satyamurthy N, Petric A, et al. Binding characteristics of radiofluorinated 6dialkylamino-2-naphthylethylidene derivatives as positron emission tomography imaging probes for beta-amyloid plaques in Alzheimer's disease. J Neurosci. 2001;21:RC189.

136. Bresjanac M, Smid LM, Vovko TD, Petric A, Barrio JR, Popovic M. Molecular-imaging probe 2-(1-[6-[(2-fluoroethyl)(methyl) amino]-2-naphthyl]ethylidene) malononitrile labels prion plaques in vitro. J Neurosci. 2003;23:8029-33.

137. Josephs KA, Martin PR, Botha H, Schwarz CG, Duffy JR, Clark $\mathrm{HM}$, et al. [(18) F]AV-1451 tau-PET and primary progressive aphasia. Ann Neurol. 2018;83:599-611.

138. Bevan-Jones WR, Cope TE, Jones PS, Passamonti L, Hong YT, Fryer TD, et al. [(18)F]AV-1451 binding in vivo mirrors the 
expected distribution of TDP-43 pathology in the semantic variant of primary progressive aphasia. J Neurol Neurosurg Psychiatry. 2018;89:1032-7.

139. Lee H, Seo S, Lee SY, Jeong HJ, Woo SH, Lee KM, et al. [18F]THK5351 PET imaging in patients with semantic variant primary progressive aphasia. Alzheimer Dis Assoc Disord. 2018;32:62-69.

140. Perez-Soriano A, Arena JE, Dinelle K, Miao Q, McKenzie J, Neilson N, et al. PBB3 imaging in Parkinsonian disorders: evidence for binding to tau and other proteins. Mov Disord. 2017;32:1016-24.

141. Cho H, Choi JY, Lee SH, Ryu YH, Lee MS, Lyoo CH. 18) FAV-1451 binds to putamen in multiple system atrophy. Mov Disord. 2017;32:171-3.

142. Harada R, Okamura N, Furumoto S, Furukawa K, Ishiki A, Tomita N, et al. 18F-THK5351: a novel PET radiotracer for imaging neurofibrillary pathology in Alzheimer disease. J Nucl Med. 2016;57:208-14.

143. Koga S, Ono M, Sahara N, Higuchi M, Dickson DW. Fluorescence and autoradiographic evaluation of tau PET ligand PBB3 to alpha-synuclein pathology. Mov Disord. 2017;32:884-92.

144. Higashi S, Iseki E, Yamamoto R, Minegishi M, Hino H, Fujisawa K, et al. Concurrence of TDP-43, tau and alpha-synuclein pathology in brains of Alzheimer's disease and dementia with Lewy bodies. Brain Res. 2007;1184:284-94.

145. Vermeiren C, Motte P, Viot D, Mairet-Coello G, Courade JP, Citron $\mathrm{M}$, et al. The tau positron-emission tomography tracer AV-1451 binds with similar affinities to tau fibrils and monoamine oxidases. Mov Disord. 2018;33:273-81.

146. Lemoine L, Leuzy A, Chiotis K, Rodriguez-Vieitez E, Nordberg A. Tau positron emission tomography imaging in tauopathies: the added hurdle of off-target binding. Alzheimers Dement. 2018;10:232-6.

147. Marquie M, Verwer EE, Meltzer AC, Kim SJW, Aguero C, Gonzalez J, et al. Lessons learned about [F-18]-AV-1451 offtarget binding from an autopsy-confirmed Parkinson's case. Acta Neuropathol Commun. 2017;5:75.

148. Fitzpatrick AWP, Falcon B, He S, Murzin AG, Murshudov G, Garringer HJ, et al. Cryo-EM structures of tau filaments from Alzheimer's disease. Nature. 2017;547:185-90.

149. Hostetler ED, Walji AM, Zeng Z, Miller P, Bennacef I, Salinas C, et al. Preclinical characterization of $18 \mathrm{~F}-\mathrm{MK}-6240$, a promising PET tracer for in vivo quantification of human neurofibrillary tangles. J Nucl Med. 2016;57:1599-606.

150. Xia CF, Arteaga J, Chen G, Gangadharmath U, Gomez LF, Kasi D, et al. [(18)F]T807, a novel tau positron emission tomography imaging agent for Alzheimer's disease. Alzheimers Dement. 2013;9:666-76.

151. Murugan NA, Nordberg A, Agren H. Different positron emission tomography tau tracers bind to multiple binding sites on the tau fibril: insight from computational modeling. ACS Chem Neurosci. 2018;9:1757-67.

152. Lemoine L, Saint-Aubert L, Marutle A, Antoni G, Eriksson JP, Ghetti B, et al. Visualization of regional tau deposits using (3)HTHK5117 in Alzheimer brain tissue. Acta Neuropathol Commun. 2015;3:40.

153. Chiotis K, Stenkrona P, Almkvist O, Stepanov V, Ferreira D, Arakawa $\mathrm{R}$, et al. Dual tracer tau PET imaging reveals different molecular targets for (11)C-THK5351 and (11)C-PBB3 in the Alzheimer brain. Eur J Nucl Med Mol Imaging. 2018;45:1605-17.

154. Jack CR, Bennett DA, Blennow K, Carrillo MC, Dunn B, Haeberlein SB, et al. NIA-AA research framework: toward a biological definition of Alzheimer's disease. Alzheimers Dement. 2018;14:535-62.

155. Jack CR, Albert MS, Knopman DS, McKhann GM, Sperling $\mathrm{RA}$, Carrillo MC, et al. Introduction to the recommendations from the National Institute on Aging-Alzheimer's Association workgroups on diagnostic guidelines for Alzheimer's disease. Alzheimers Dement. 2011;7:257-62.

156. Albert MS, DeKosky ST, Dickson D, Dubois B, Feldman HH, Fox NC, et al. The diagnosis of mild cognitive impairment due to Alzheimer's disease: recommendations from the National Institute on Aging-Alzheimer's Association workgroups on diagnostic guidelines for Alzheimer's disease. Alzheimers Dement. 2011;7:270-9.

157. McKhann GM, Knopman DS, Chertkow H, Hyman BT, Jack $\mathrm{CR}$, Kawas $\mathrm{CH}$, et al. The diagnosis of dementia due to Alzheimer's disease: recommendations from the National Institute on Aging-Alzheimer's Association workgroups on diagnostic guidelines for Alzheimer's disease. Alzheimers Dement. 2011;7:263-9.

158. Sperling RA, Aisen PS, Beckett LA, Bennett DA, Craft S, Fagan AM, et al. Toward defining the preclinical stages of Alzheimer's disease: recommendations from the National Institute on AgingAlzheimer's Association workgroups on diagnostic guidelines for Alzheimer's disease. Alzheimers Dement. 2011;7:280-92.

159. Fagan AM, Mintun MA, Mach RH, Lee SY, Dence CS, Shah $\mathrm{AR}$, et al. Inverse relation between in vivo amyloid imaging load and cerebrospinal fluid Abeta42 in humans. Ann Neurol. 2006;59:512-9.

160. Landau SM, Lu M, Joshi AD, Pontecorvo M, Mintun MA, Trojanowski JQ, et al. Comparing positron emission tomography imaging and cerebrospinal fluid measurements of beta-amyloid. Ann Neurol. 2013;74:826-36.

161. Palmqvist S, Zetterberg H, Mattsson N, Johansson P, Alzheimer's Disease Neuroimaging I, Minthon L, et al. Detailed comparison of amyloid PET and CSF biomarkers for identifying early Alzheimer disease. Neurology. 2015;85:1240-9.

162. Palmqvist S, Mattsson N, Hansson O, Alzheimer's Disease Neuroimaging I. Cerebrospinal fluid analysis detects cerebral amyloid-beta accumulation earlier than positron emission tomography. Brain. 2016;139(Pt 4):1226-36.

163. Mattsson N, Insel PS, Donohue M, Landau S, Jagust WJ, Shaw $\mathrm{LM}$, et al. Independent information from cerebrospinal fluid amyloid-beta and florbetapir imaging in Alzheimer's disease. Brain. 2015;138(Pt 3):772-83.

164. Vlassenko AG, McCue L, Jasielec MS, Su Y, Gordon BA, Xiong $\mathrm{C}$, et al. Imaging and cerebrospinal fluid biomarkers in early preclinical alzheimer disease. Ann Neurol. 2016;80:37987.

165. Fagan AM, Xiong C, Jasielec MS, Bateman RJ, Goate AM, Benzinger TL, et al. Longitudinal change in CSF biomarkers in autosomal-dominant Alzheimer's disease. Sci Transl Med. 2014;6:226ra230.

166. Mattsson N, Scholl M, Strandberg O, Smith R, Palmqvist S, Insel PS, et al. (18)F-AV-1451 and CSF T-tau and P-tau as biomarkers in Alzheimer's disease. EMBO Mol Med. 2017;9:1212-23.

167. Blennow K, Wallin A, Agren H, Spenger C, Siegfried J, Vanmechelen E. Tau protein in cerebrospinal fluid: a biochemical marker for axonal degeneration in Alzheimer disease? Mol Chem Neuropathol. 1995;26:231-45.

168. Mann DM, Hardy J. Amyloid or tau: the chicken or the egg? Acta Neuropathol. 2013;126:609-13.

169. Braak H, Del Tredici K. Reply: the early pathological process in sporadic Alzheimer's disease. Acta Neuropathol. 2013;126:6158.

170. Attems J, Jellinger KA. Amyloid and tau: neither chicken nor egg but two partners in crime! Acta Neuropathol. 2013;126:619-21.

171. Price JL, Morris JC. Tangles and plaques in nondemented aging and "preclinical" Alzheimer's disease. Ann Neurol. 1999;45:358-68. 
172. Jack CR, Knopman DS, Jagust WJ, Petersen RC, Weiner MW, Aisen PS, et al. Tracking pathophysiological processes in Alzheimer's disease: an updated hypothetical model of dynamic biomarkers. Lancet Neurol. 2013;12:207-16.

173. Murray ME, Lowe VJ, Graff-Radford NR, Liesinger AM, Cannon A, Przybelski SA, et al. Clinicopathologic and 11CPittsburgh compound B implications of Thal amyloid phase across the Alzheimer's disease spectrum. Brain. 2015;138(Pt 5):1370-81.

174. Thal DR, Beach TG, Zanette M, Heurling K, Chakrabarty A, Ismail A, et al. [(18)F]flutemetamol amyloid positron emission tomography in preclinical and symptomatic Alzheimer's disease: specific detection of advanced phases of amyloid-beta pathology. Alzheimers Dement. 2015;11:975-85.

175. Sperling R, Mormino E, Johnson K. The evolution of preclinical Alzheimer's disease: implications for prevention trials. Neuron. 2014;84:608-22.

176. Mishra S, Gordon BA, Su Y, Christensen J, Friedrichsen K, Jackson $\mathrm{K}$, et al. AV-1451 PET imaging of tau pathology in preclinical Alzheimer disease: defining a summary measure. Neuroimage. 2017;161:171-8.

177. Lowe VJ, Wiste HJ, Senjem ML, Weigand SD, Therneau TM, Boeve BF, et al. Widespread brain tau and its association with ageing, Braak stage and Alzheimer's dementia. Brain. 2018;141:271-87.

178. Villemagne VL, Dore V, Burnham SC, Masters CL, Rowe CC. Imaging tau and amyloid-beta proteinopathies in Alzheimer disease and other conditions. Nat Rev Neurol. 2018;14:225-36.

179. Iaccarino L, Tammewar G, Ayakta N, Baker SL, Bejanin A, Boxer AL, et al. Local and distant relationships between amyloid, tau and neurodegeneration in Alzheimer's Disease. Neuroimage Clin. 2018;17:452-64.

180. Lockhart SN, Scholl M, Baker SL, Ayakta N, Swinnerton KN, Bell RK, et al. Amyloid and tau PET demonstrate region-specific associations in normal older people. Neuroimage. 2017;150:191-9.

181. Sepulcre J, Sabuncu MR, Li Q, El Fakhri G, Sperling R, Johnson KA. Tau and amyloid beta proteins distinctively associate to functional network changes in the aging brain. Alzheimers Dement. 2017;13:1261-9.

182. Jack CR, Knopman DS, Jagust WJ, Shaw LM, Aisen PS, Weiner MW, et al. Hypothetical model of dynamic biomarkers of the Alzheimer's pathological cascade. Lancet Neurol. 2010;9:119-28.

183. Bejanin A, Schonhaut DR, La Joie R, Kramer JH, Baker SL, Sosa N, et al. Tau pathology and neurodegeneration contribute to cognitive impairment in Alzheimer's disease. Brain. 2017;140:3286-3300.

184. Saint-Aubert L, Almkvist O, Chiotis K, Almeida R, Wall A, Nordberg A. Regional tau deposition measured by [18F] THK5317 positron emission tomography is associated to cognition via glucose metabolism in Alzheimer's disease. Alzheimers Res Ther. 2016;8:38

185. Mattsson N, Smith R, Strandberg O, Palmqvist S, Scholl M, Insel PS, et al. Comparing (18)F-AV-1451 with CSF t-tau and ptau for diagnosis of Alzheimer disease. Neurology. 2018;90: e388-e395.

186. La Joie R, Bejanin A, Fagan AM, Ayakta N, Baker SL, Bourakova V, et al. Associations between [(18)F]AV1451 tau PET and CSF measures of tau pathology in a clinical sample. Neurology. 2018;90:e282-e290.

187. Chhatwal JP, Schultz AP, Marshall GA, Boot B, Gomez-Isla T, Dumurgier J, et al. Temporal T807 binding correlates with CSF tau and phospho-tau in normal elderly. Neurology. 2016;87: $920-6$.
188. Sato C, Barthelemy NR, Mawuenyega KG, Patterson BW, Gordon BA, Jockel-Balsarotti J, et al. Tau kinetics in neurons and the human central nervous system. Neuron. 2018;97:128498 e1287.

189. Blennow K, Hampel H. CSF markers for incipient Alzheimer's disease. Lancet Neurol. 2003;2:605-13.

190. Meredith JE, Sankaranarayanan S, Guss V, Lanzetti AJ, Berisha F, Neely RJ, et al. Characterization of novel CSF tau and ptau biomarkers for Alzheimer's disease. PLoS ONE. 2013;8:e76523.

191. Hanseeuw BJ, Betensky RA, Schultz AP, Papp KV, Mormino EC, Sepulcre J, et al. Fluorodeoxyglucose metabolism associated with tau-amyloid interaction predicts memory decline. Ann Neurol. 2017;81:583-96.

192. Bischof GN, Jessen F, Fliessbach K, Dronse J, Hammes J, Neumaier B, et al. Impact of tau and amyloid burden on glucose metabolism in Alzheimer's disease. Ann Clin Transl Neurol. 2016;3:934-9.

193. Whitwell JL, Graff-Radford J, Tosakulwong N, Weigand SD, Machulda MM, Senjem ML, et al. Imaging correlations of tau, amyloid, metabolism, and atrophy in typical and atypical Alzheimer's disease. Alzheimer Dement. 2018.

194. Leuzy A, Rodriguez-Vieitez E, Saint-Aubert L, Chiotis K, Almkvist O, Savitcheva I, et al. Longitudinal uncoupling of cerebral perfusion, glucose metabolism, and tau deposition in Alzheimer's disease. Alzheimer Dement. 2018;14:652-63.

195. LaPoint MR, Chhatwal JP, Sepulcre J, Johnson KA, Sperling RA, Schultz AP. The association between tau PET and retrospective cortical thinning in clinically normal elderly. Neuroimage. 2017;157:612-22.

196. Das SR, Xie L, Wisse LEM, Ittyerah R, Tustison NJ, Dickerson $\mathrm{BC}$, et al. Longitudinal and cross-sectional structural magnetic resonance imaging correlates of AV-1451 uptake. Neurobiol Aging. 2018;66:49-58.

197. Jacobs HIL, Hedden T, Schultz AP, Sepulcre J, Perea RD, Amariglio RE, et al. Structural tract alterations predict downstream tau accumulation in amyloid-positive older individuals. Nat Neurosci. 2018;21:424-31.

198. Ahmed Z, Cooper J, Murray TK, Garn K, McNaughton E, Clarke $\mathrm{H}$, et al. A novel in vivo model of tau propagation with rapid and progressive neurofibrillary tangle pathology: the pattern of spread is determined by connectivity, not proximity. Acta Neuropathol. 2014;127:667-83.

199. de Calignon A, Polydoro M, Suarez-Calvet M, William C, Adamowicz DH, Kopeikina KJ, et al. Propagation of tau pathology in a model of early Alzheimer's disease. Neuron. 2012;73:685-97.

200. Villemagne VL, Furumoto S, Fodero-Tavoletti MT, Mulligan RS, Hodges J, Harada R, et al. In vivo evaluation of a novel tau imaging tracer for Alzheimer's disease. Eur J Nucl Med Mol Imaging. 2014;41:816-26.

201. Hesse C, Rosengren L, Andreasen N, Davidsson P, Vanderstichele $\mathrm{H}$, Vanmechelen $\mathrm{E}$, et al. Transient increase in total tau but not phospho-tau in human cerebrospinal fluid after acute stroke. Neurosci Lett. 2001;297:187-90.

202. Ost M, Nylen K, Csajbok L, Ohrfelt AO, Tullberg M, Wikkelso $\mathrm{C}$, et al. Initial CSF total tau correlates with 1-year outcome in patients with traumatic brain injury. Neurology. 2006;67:1600-4.

203. Buerger K, Otto M, Teipel SJ, Zinkowski R, Blennow K, DeBernardis J, et al. Dissociation between CSF total tau and tau protein phosphorylated at threonine 231 in Creutzfeldt-Jakob disease. Neurobiol Aging. 2006;27:10-15.

204. Skillback T, Rosen C, Asztely F, Mattsson N, Blennow K, Zetterberg H. Diagnostic performance of cerebrospinal fluid total tau and phosphorylated tau in Creutzfeldt-Jakob disease: results 
from the Swedish Mortality Registry. JAMA Neurol. 2014;71:476-83.

205. Nelson PT, Alafuzoff I, Bigio EH, Bouras C, Braak H, Cairns $\mathrm{NJ}$, et al. Correlation of Alzheimer disease neuropathologic changes with cognitive status: a review of the literature. J Neuropathol Exp Neurol. 2012;71:362-81.

206. Ghoshal N, Garcia-Sierra F, Wuu J, Leurgans S, Bennett DA, Berry RW, et al. Tau conformational changes correspond to impairments of episodic memory in mild cognitive impairment and Alzheimer's disease. Exp Neurol. 2002;177:475-93.

207. Shimada H, Kitamura S, Shinotoh H, Endo H, Niwa F, Hirano S, et al. Association between Abeta and tau accumulations and their influence on clinical features in aging and Alzheimer's disease spectrum brains: a [(11)C]PBB3-PET study. Alzheimers Dement (Amst). 2017;6:11-20.

208. Kang JM, Lee SY, Seo S, Jeong HJ, Woo SH, Lee H, et al. Tau positron emission tomography using [(18)F]THK5351 and cerebral glucose hypometabolism in Alzheimer's disease. Neurobiol Aging. 2017;59:210-9.

209. Cho H, Choi JY, Lee SH, Lee JH, Choi YC, Ryu YH, et al. Excessive tau accumulation in the parieto-occipital cortex characterizes early-onset Alzheimer's disease. Neurobiol Aging. 2017;53:103-11.

210. Maass A, Lockhart SN, Harrison TM, Bell RK, Mellinger T, Swinnerton K, et al. Entorhinal tau pathology, episodic memory decline, and neurodegeneration in aging. $J$ Neurosci. 2018;38:530-43.

211. Buckley RF, Hanseeuw B, Schultz AP, Vannini P, Aghjayan SL, Properzi MJ, et al. Region-specific association of subjective cognitive decline with tauopathy independent of global betaamyloid burden. JAMA Neurol. 2017;74:1455-63.

212. Royall DR. Location, location, location! Neurobiol Aging. 2007;28:1481-2. discussion 1483

213. Furst AJ, Rabinovici GD, Rostomian AH, Steed T, Alkalay A, Racine C, et al. Cognition, glucose metabolism and amyloid burden in Alzheimer's disease. Neurobiol Aging. 2012;33: 215-25.

214. Maass A, Landau S, Baker SL, Horng A, Lockhart SN, La Joie $\mathrm{R}$, et al. Comparison of multiple tau-PET measures as biomarkers in aging and Alzheimer's disease. Neuroimage. 2017;157:448-63.

215. Hoenig MC, Bischof GN, Seemiller J, Hammes J, Kukolja J, Onur OA, et al. Networks of tau distribution in Alzheimer's disease. Brain. 2018;141:568-81.

216. Whitwell JL, Graff-Radford J, Tosakulwong N, Weigand SD, Machulda M, Senjem ML, et al. [(18) F]AV-1451 clustering of entorhinal and cortical uptake in Alzheimer's disease. Ann Neurol. 2018;83:248-57.

217. Thambisetty M, An Y, Nalls M, Sojkova J, Swaminathan S, Zhou Y, et al. Effect of complement CR1 on brain amyloid burden during aging and its modification by APOE genotype. Biol Psychiatry. 2013;73:422-8.

218. Patterson BW, Elbert DL, Mawuenyega KG, Kasten T, Ovod V, Ma S, et al. Age and amyloid effects on human central nervous system amyloid-beta kinetics. Ann Neurol. 2015;78:439-53.

219. Vemuri P, Knopman DS, Lesnick TG, Przybelski SA, Mielke MM, Graff-Radford J, et al. Evaluation of Amyloid Protective Factors and Alzheimer Disease Neurodegeneration Protective Factors in Elderly Individuals. JAMA Neurol. 2017;74:718-26.

220. Duyckaerts C. Tau pathology in children and young adults: can you still be unconditionally baptist? Acta Neuropathol. 2011;121:145-7.

221. Duyckaerts C, Uchihara T, Seilhean D, He Y, Hauw JJ. Dissociation of Alzheimer type pathology in a disconnected piece of cortex. Acta Neuropathol. 1997;93:501-7.
222. Mesulam MM. Neuroplasticity failure in Alzheimer's disease: bridging the gap between plaques and tangles. Neuron. 1999;24:521-9.

223. Small SA, Duff K. Linking Abeta and tau in late-onset Alzheimer's disease: a dual pathway hypothesis. Neuron. 2008;60:53442.

224. Cho H, Lee HS, Choi JY, Lee JH, Ryu YH, Lee MS, et al. Predicted sequence of cortical tau and amyloid-beta deposition in Alzheimer disease spectrum. Neurobiol Aging. 2018;68:76-84.

225. Corey DR. Nusinersen, an antisense oligonucleotide drug for spinal muscular atrophy. Nat Neurosci. 2017;20:497-9.

226. Finkel RS, Chiriboga CA, Vajsar J, Day JW, Montes J, De Vivo DC, et al. Treatment of infantile-onset spinal muscular atrophy with nusinersen: a phase 2, open-label, dose-escalation study. Lancet. 2016;388:3017-26.

227. Asghar U, Witkiewicz AK, Turner NC, Knudsen ES. The history and future of targeting cyclin-dependent kinases in cancer therapy. Nat Rev Drug Discov. 2015;14:130-46.

228. Khalil HS, Mitev V, Vlaykova T, Cavicchi L, Zhelev N. Discovery and development of Seliciclib. How systems biology approaches can lead to better drug performance. J Biotechnol. 2015;202:40-49.

229. Panza F, Solfrizzi V, Seripa D, Imbimbo BP, Lozupone M, Santamato A, et al. Tau-centric targets and drugs in clinical development for the treatment of Alzheimer's disease. Biomed Res Int. 2016;2016:3245935.

230. Wischik CM, Edwards PC, Lai RY, Roth M, Harrington CR. Selective inhibition of Alzheimer disease-like tau aggregation by phenothiazines. Proc Natl Acad Sci USA. 1996;93:11213-8.

231. Congdon EE, Sigurdsson EM Tau-targeting therapies for Alzheimer disease. Nat Rev Neurol. 2018;14:399-415.

232. At CTAD, Tau PET Emerges as Favored Outcome Biomarker for Trials. https://www.alzforum.org/news/conference-coverage/ ctad-tau-pet-emerges-favored-outcome-biomarker-trials. 2017. Accessed 2017.

233. Hansson O, Mormino EC. Is longitudinal tau PET ready for use in Alzheimer's disease clinical trials? Brain. 2018;141:1241-4.

234. Palmqvist S, Scholl M, Strandberg O, Mattsson N, Stomrud E, Zetterberg $\mathrm{H}$, et al. Earliest accumulation of beta-amyloid occurs within the default-mode network and concurrently affects brain connectivity. Nat Commun. 2017;8:1214.

235. McDade E, Bateman RJ. Tau positron emission tomography in autosomal dominant alzheimer disease: small windows, big picture. JAMA Neurol. 2018;75:536-8.

236. Beyer L, Meyer-Wilmes J, Schonecker S, Schnabel J, Brendel E, Prix C, et al. Clinical routine FDG-PET imaging of suspected progressive supranuclear palsy and corticobasal degeneration: a gatekeeper for subsequent tau-PET imaging? Front Neurol. 2018;9:483.

237. Rohrer JD, Rosen HJ. Neuroimaging in frontotemporal dementia. Int Rev Psychiatry. 2013;25:221-9.

238. Nordberg A. Molecular imaging in Alzheimer's disease: new perspectives on biomarkers for early diagnosis and drug development. Alzheimers Res Ther. 2011;3:34.

239. Okamura N, Furumoto S, Harada R, Tago T, Yoshikawa T, Fodero-Tavoletti M, et al. Novel 18F-labeled arylquinoline derivatives for noninvasive imaging of tau pathology in Alzheimer disease. J Nucl Med. 2013;54:1420-7.

240. Tago T, Furumoto S, Okamura N, Harada R, Adachi H, Ishikawa Y, et al. Structure-activity relationship of 2-arylquinolines as PET imaging tracers for tau pathology in Alzheimer disease. $\mathrm{J}$ Nucl Med. 2016;57:608-14.

241. Honer M, Gobbi L, Knust H, Kuwabara H, Muri D, Koerner M, et al. Preclinical evaluation of (18)F-RO6958948, (11)CRO6931643, and (11)C-RO6924963 as novel PET radiotracers 
for imaging tau aggregates in Alzheimer Disease. J Nucl Med. 2018;59:675-81.

242. Preclinical characterization of PI-2620. A novel tau pet tracer for detection of tau in ad and other tauopathies. Proceedings of the Alzheimer's Association International Conference. London, UK: Alzheimer's \& Dementia; 2017;13:P141-2. https://doi.org/10. 1007/s11682-018-9847-7. [Epub ahead of print].

243. Lois C, Gonzalez I, Johnson KA, Price JC. PET imaging of tau protein targets: a methodology perspective. Brain Imaging Behav. 2018. https://doi.org/10.1007/s11682-018-98477.

244. Ono M, Kitamura S, Shimada H, Sahara N, Takuwa H, Yoshiyama Y, et al. Development of novel tau PET tracers, [18F]AM-
PBB3 and [18F]PM-PBB3. Human Amyloid Imaging, Miami, Florida, 2017, p. 34.

245. Pre-clinical characterization of the novel tau PET ligand $[18 \mathrm{~F}]-$ JNJ'067. Proceedings of the Alzheimer's Association International Conference. London, UK: Alzheimer's \& Dementia; 2017;13:P1069.

246. Ishiki A, Harada R, Okamura N, Tomita N, Rowe CC, Villemagne VL, et al. Tau imaging with [(18) F]THK-5351 in progressive supranuclear palsy. Eur J Neurol. 2017;24:130-6.

247. Lemoine L, Saint-Aubert L, Nennesmo I, Gillberg PG, Nordberg A. Cortical laminar tau deposits and activated astrocytes in Alzheimer's disease visualised by (3)H-THK5117 and (3)Hdeprenyl autoradiography. Sci Rep. 2017;7:45496. 